Revista lus et Praxis, Año 23, No 1, 2017, pp. 195 - 246

ISSN 0717 - 2877

Universidad de Talca - Facultad de Ciencias Jurídicas y Sociales

La prueba ilícita en las diligencias limitativas de derechos fundamentales en el proceso penal chileno.

Algunos problemas

Raúl Núñez Ojeda - Claudio Correa Zacarías

Trabajo recibido el 8 de marzo de 2016 y aprobado el 9 de abril de 2016

\title{
La prueba ilícita en las diligencias limitativas de derechos fundamentales en el proceso penal chileno. Algunos problemas*
}

\author{
THE ILLICIT EVIDENCE IN THE PROCEEDINGS THAT LIMIT \\ FUNDAMENTAL RIGHTS IN CHILEAN CRIMINAL LAW PROCESS. SOME ISSUES
}

\author{
Raúl NúÑez OJeda** \\ Claudio Correa Zacarías***
}

\begin{abstract}
RESUMEN
El presente artículo pretende investigar los problemas que presentan las diligencias limitativas de derechos fundamentales, en especial de las diligencias de entrada y registro, incautación y control de identidad reguladas en el Código Procesal Penal chileno. En efecto, el estudio se centra en los problemas de ilicitud probatoria de las diligencias antes mencionadas desde una perspectiva dogmática como también jurisprudencial.
\end{abstract}

\section{ABSTRACT}

This article aims to investigate the problems presented by the limitant formalities of the fundamental rights, especially the formalities for entry and registration, seizure and identity control regulated in the Chilean Procedure Code. In fact, the study focuses on the problems of unlawful probation of the aforementioned formalities from a dogmatic perspective as well as jurisprudence.

PALABRAS CLAVE

Prueba ilícita, Medidas limitativas de derechos fundamentales, Diligencia de entrada y registro, Incautación, control de identidad y Derecho Procesal Penal.

KEYWORDS

Ilicit evidence, Limitant formalities of fundamental rights, Formalities of entry and registration, Seizure, Identity control, Criminal Procedural Law.

\footnotetext{
* Este trabajo se enmarca dentro del proyecto Fondecyt regular № 1130422, que lleva por título: "Formulación de una teoría general de las medidas coercitivas en el proceso penal chileno: estudio dogmático y crítico", cuyo investigador principal es el profesor Dr. Guillermo Oliver Calderón de la Pontificia Universidad Católica de Valparaíso.

** Licenciado en Ciencias Jurídicas por la Universidad de Valparaíso (Chile); Doctor en Derecho por la Universidad Pompeu Fabra de Barcelona (España); Profesor de Derecho Procesal en la Pontificia Universidad Católica de Valparaíso (Chile). Correo electrónico: raul.nunez@ucv.cl.

*** Licenciado en Ciencias Jurídicas por la Universidad de Chile, Magíster en Derecho Penal y Ciencias Penales por la Pontificia Universidad Católica de Valparaíso, Magistrado de tribunal de juicio oral en lo penal. Correo electrónico: ccorreaz@vtr.net.
} 


\section{Introducción}

No es posible concebir la persecución penal, ni menos el ejercicio del poder punitivo, sin cierto grado de afectación a las garantías individuales esenciales, como la libertad ambulatoria, la propiedad, la inviolabilidad de las comunicaciones, la intimidad del hogar, etc. Un Estado no dispuesto a aterrizar a este nivel la operatividad de su justicia, conculcando, llegado el caso, derechos esenciales (en ciertos casos y medidas), estaría condenado a la insustancialidad y hasta el menosprecio ciudadano. La legitimidad del Estado sancionador, que ha expropiado el conflicto penal a los particulares, sólo se alcanza, entre otros requerimientos, cuando se entrega a la ciudadanía una garantía mínima de cierto nivel de eficacia en la aplicación de las normas sancionatorias.

Esta coexistencia y pugna entre la persecución penal y los derechos de los justiciados, constituye una ecuación decisiva para definir la calidad de justicia que se pretende. La vigencia de un Estado democrático de derecho demanda que ambos extremos en la ecuación sean tenidos en cuenta y cohabiten armónicamente en el proceso penal. Este delicado equilibrio entre derechos ciudadanos y eficacia de la persecución, por ser un asunto de una casuística inherente a su naturaleza, generalmente, no se encuentra resuelto de forma anticipada por el legislador y se precisa que el juez construya caso a caso la solución particular, autorizando determinadas medidas intrusivas o excluyendo prueba de la valoración definitiva del caso.

En las líneas que siguen, abordaremos aspectos generales de las medidas intrusivas en un contexto investigativo, profundizando el estudio de ciertos elementos regulatorios relevantes para algunas de ellas. También nos detendremos en la institución de la prueba ilícita, en aquella parte que tenga importancia para discernir la validez o no de un material probatorio generado por una medida intrusiva. Terminaremos exponiendo una serie de "casos difíciles", que juzgamos de regular ocurrencia en la práctica forense, así como complejos de resolver mediante fórmulas preestablecidas. Pretendemos proponer criterios para responder a la interrogante si la prueba generada por determinadas medidas intrusivas son o no válidas, fundados ellos en razones positivas y dogmáticas, que permitan solucionar estos casos seleccionados.

El establecimiento de estos criterios se estima como una necesidad urgente en nuestro quehacer procesal, puesto que el silencio dogmático, en la práctica, permite que las exigencias para la validación probatoria del material obtenido con estas medidas, sea tan diverso como jueces intervienen en las causas, reduciendo el problema a un asunto casi de mera subjetividad o intuición del intérprete.

Se pretende, en definitiva, constituir un aporte hacia la construcción de reglas y estándares de aplicación generalizable, en materia de admisión probatoria de elementos obtenidos mediante la aplicación de medidas intrusivas. 


\section{Los derechos fundamentales y el proceso penal}

\subsection{Restricción de los derechos fundamentales}

Como primer tema cabe referirse a la restricción de los derechos fundamentales como una figura jurídica dirigida a la protección eficaz de dichos derechos. En particular, ha de tomarse en cuenta fundamentalmente la noción clásica de dicho instrumento, esto es, aquella que sirve para su salvaguarda frente a actuaciones de los poderes públicos ${ }^{1}$.

La jurisprudencia de los Tribunales Constitucionales de algunos países de Europa establece, con carácter general, la correspondencia entre la idea de la conformidad constitucional, exigible a toda medida estatal que incide sobre derechos fundamentales, y la expresión "restricción" o "limitación" de tales derechos. Dicha vinculación se ha argumentado con la afirmación, generalmente admitida por los mencionados tribunales, que ni los derechos fundamentales son absolutos ni tampoco sus límites. Derechos y límites se sitúan en un régimen de "concurrencia normativa", en el sentido de que actúan recíprocamente, si bien, ante la posición privilegiada que los derechos fundamentales ocupan en nuestro ordenamiento, debe restringirse el alcance de las normas limitadores que actúan sobre ellos o, lo que es lo mismo, los límites deben interpretarse restrictivamente y en el sentido más favorable a la eficacia y esencia de dichos derechos ${ }^{2}$.

Así las cosas, como noción de restricción de derechos fundamentales no ha sido suficientemente elaborada por nuestra doctrina, tal circunstancia conduce a la búsqueda de tal concepto en otros ordenamientos jurídicos, como el alemán, donde ha sido objeto de elaboración doctrinal, con el propósito de incorporar el término equivalente a nuestro ordenamiento jurídico ${ }^{3}$.

De conformidad con la mencionada concepción doctrinal germana, las medidas restrictivas de derechos fundamentales pueden definirse como aquellas intromisiones vulneradoras prima facie del ámbito de protección de los derechos fundamentales, lo que conforma el supuesto de hecho de dichos derechos que precisan, por este motivo, de justificación de acuerdo con el principio de proporcionalidad ${ }^{4}$.

En cuanto a su naturaleza jurídica, la figura jurídica de la restricción de derechos fundamentales constituye un mecanismo de control de la

1 Cabezudo Bajo (2004), p. 27.

2 Cabezudo Bajo (2004), p. 28.

3 Schmalz (1997), pp. 55 y ss.; ECkhoff (1992), p. 21, y Pieroth y SChlink (1989), pp. 336-337.

4 Sobre el principio de proporcionalidad, ver por todos: BeRnAL (2005). Para el enjuiciamiento criminal ver: González-Cuéllar (1990), especialmente, pp. 49 y ss. 
constitucionalidad de las actuaciones estatales lesivas de los mencionados derechos que persiguen dos funciones. De un lado, una finalidad principal y positiva que se concreta en su carácter de "límite de límites", al igual que otros instrumentos jurídicos, como la reserva de ley orgánica, la garantía del contenido esencial de los derechos fundamentales, la motivación de la limitación del derecho y el cumplimiento del principio de proporcionalidad ${ }^{5}$. De otro lado, una función negativa y fiduciaria de la primera, como es la determinación aproximada del contenido esencial de los derechos fundamentales, de acuerdo con la teoría "subjetiva relativa" 6 .

En este sentido, mientras la teoría subjetiva absoluta afirma que el núcleo esencial en cada derecho en ningún caso puede ser afectado, de acuerdo con la teoría subjetiva relativa postulada por Alexy, el contenido esencial es el resultado de una ponderación, esto es, los límites que responden al principio de proporcionalidad implican que no se lesiona la garantía del contenido esencial, aunque en el caso particular no dejen nada del derecho fundamental, de manera que la garantía del contenido esencial se reduce al principio de proporcionalidad ${ }^{7}$. Dicha postura es la mantenida por el Tribunal Constitucional español pues, si bien ha postulado que se aplican excepcionalmente ambas garantías, exige fundamentalmente, en caso de restricciones efectuadas por el Poder Judicial, el cumplimiento del principio de proporcionalidad ${ }^{8}$.

Por tanto, la restricción de derechos fundamentales y el contenido esencial de los mencionados derechos constituyen dos mecanismos de protección de los derechos fundamentales que conforman las dos caras de una misma moneda.

En cuanto a los límites a los derechos fundamentales, Alexy parte de la "teoría externa", que se corresponde con la "teoría de los límites inmanentes". En particular, Alexy manifiesta que conforme a la "teoría externa", cabe distinguir el derecho, de un lado, y sus límites o restricciones, por otro ${ }^{9}$. Entre ellos opera una relación especial, denominada de limitación o restricción, tan sólo

\footnotetext{
${ }^{5}$ A este respecto, se señala que constituyen "límites de límites" el principio de proporcionalidad o prohibición de exceso, garantía de contenido esencial (art. 19.2 GG alemana), la prohibición de una ley limitadora especial (art. 29.1.1. GG alemana) y la cita de precepto (art. 19.1.2 GG alemana). Así lo indica: Pieroth y SCHLINK (1989), p. 72.

${ }^{6}$ Cabezudo Bajo (2004), p. 30.

7 CABEZUdo Bajo (2004), p. 30. Según la teoría subjetiva que se contrapone a la objetividad, hay posiciones respecto a las cuales no existe ninguna razón superior que las desplace, como ha afirmado Alexy en: Alexy (1986), p. 290 y pp. 288-291. También sigue la distinción: PierOth y SCHLINK (1989), pp. 76-78.

${ }^{8}$ En este sentido ver: STC 137/1990, de 19 de julio de 1990 (FJ. $6^{\circ}$ ), exige el cumplimiento de la garantía del contenido esencial, así como el principio de proporcionalidad.

${ }^{9}$ La distinción entre la teoría externa y la teoría interna ha sido puesta de manifiesto por ECKHOFF (1992), pp. 12 y 13 y por Alexy (1986), pp. 268-269.
} 
cuando concurre una necesidad, externa al derecho, de compatibilizarlos con otros derechos individuales y bienes colectivos ${ }^{10}$.

Siguiendo esta doctrina, nuestro Tribunal Constitucional ha señalado que es constitucionalmente admisible limitar un derecho fundamental, sin impedir su libre ejercicio, pero para ello dichas restricciones deben cumplir estrictas condiciones, entre ellas, la de estar establecidas con parámetros incuestionables, esto es, ser razonables y justificadas ${ }^{11}$.

Sobre lo anterior, nos referiremos con más detalle infra (4.8.) al tratar sobre los límites de la exclusión probatoria por ilicitud y de la metodología para solucionar posibles conflictos en esta temática.

\subsection{Investigación penal, medidas intrusivas y recolección probatoria}

La investigación criminal constituye un constante ejercicio de formulación de hipótesis intelectuales, planteamiento de conjeturas y elaboración de posibles explicaciones que se correspondan con aquella parte de los hechos que es susceptible de ser demostrada a través de la prueba. El desarrollo de este ejercicio ya evidencia que la justicia -y especialmente la criminal-se encuentra íntimamente asociada al concepto de "verdad". Por cierto, no nos referimos a ésta en su dimensión filosófica, metafísica ni menos aún religiosa, sino que usamos este vocablo para aludir a un concepto mucho más modesto y menos pretencioso. Para los efectos procesales penales, siguiendo a Maier, entendemos por "verdad" la correspondencia que guarda la hipótesis que sostiene un sujeto respecto de un hecho con relevancia penal, y lo que se haya podido evidenciar de ese hecho, mediante los mecanismos que la ley prevé12.

De lo anteriormente dicho fluye que la actividad investigativa y en concreto la labor de recolección probatoria, constituyen un conjunto de acciones llevadas adelante por el órgano que sostiene la persecución penal, en términos generales, el Ministerio Público, para poder establecer la verdad, en los términos que ella sea factible de obtener. El cúmulo de datos que se obtenga como resultado de este proceso permitirá al Ministerio Público, decidir si el hecho indagado corresponde o no a un suceso con relevancia penal y, en la afirmativa, dirimir si está en condiciones de enervar, con relativas posibilidades de éxito, la acción penal en contra del o los sujetos que aparecen como responsables. De la última idea expuesta y siguiendo en ello a los profesores Duce y Riego, puede afirmarse

\footnotetext{
10 Cabezudo Bajo (2004), p. 32.

11 STC No 946-2007 "FM Seguridad S.A.", inaplicabililidad por inconstitucionalidad, considerandos 43-46. Esta sentencia sigue la jurisprudencia de los roles Nºs. 226 y 280.

12 Maier (2011), pp. 71-72.
} 
que la etapa investigativa sólo busca reunir información para el persecutor, con el objetivo que prepare actuaciones futuras (de cara a un juicio o al término anticipado de la causa). El reunir trazos de información, organizarla, ponderarla, intentando unificarla bajo una misma teoría interpretativa del evento indagado, es un ejercicio de gestión de datos desprovisto de cualquier valor probatorio o jurisdiccional intrínseco. Lo reunido durante la investigación sólo será prueba cuando se haya producido e incorporado en forma al juicio ${ }^{13}$.

La labor investigativa, por cierto, no se desarrolla en un mundo aséptico y abstracto, sino que se ejecuta en una sociedad de personas estrechamente relacionadas entre sí y titulares de derechos e intereses constitucionalmente protegidos. Al anterior factor, debe sumarse el hecho que los delitos por cierto procuran ser cometidos en la clandestinidad, silenciando cualquier rastro o vestigio que pueda hacerlos visibles o el camino para llegar a sus responsables. El delito en general subyace oculto y es necesario que el Estado hurgue para que éste salga a la luz. En este contexto, las acciones investigativas del Estado persecutor invaden las esferas jurídicas de los ciudadanos, provocando en ocasiones vulneraciones o amenazas a los derechos esenciales. Por cierto que algunas acciones investigativas podrán no conculcar ni amenazar garantía ciudadana alguna. Sin embargo, debe admitirse que una gran cantidad de diligencias investigativas, en mayor o menor medida, conllevan una amenaza o derechamente una lesión a algunos derechos sustanciales de las personas. Así, muchas veces el investigar con relativa eficacia demandará realizar registros corporales, revisiones de equipajes, allanamiento de inmuebles, interceptar comunicaciones, entre otras medidas, cada una de las cuales tiene la potencialidad de afectar derechos fundamentales reconocidos por la Constitución, tales como la libertad ambulatoria, la propiedad, la intimidad, la privacidad de las comunicaciones, etc.

Establecer la intangibilidad absoluta de los derechos ciudadanos de cara a la investigación penal sería, sin eufemismos, condenar a muerte cualquier expectativa de contar con un sistema procesal penal. La actividad investigativa mantiene una relación indisociable con los derechos fundamentales, regulando su afectación. Así lo afirma Horvitz al señalar que "... es evidente [que]... durante la investigación preparatoria se produce de modo inevitable una tensión entre la necesidad de eficacia de la persecución penal del Estado y el respeto de las garantías individuales comprometidas con dicha persecución..." (Horvitz y López, 2002, I, p. 447) ${ }^{14}$.

13 Duce y Riego (2007), p. 120.

${ }^{14}$ Véase también BoflLL (1988), p. 227. 
Es por lo anterior, y ante la prístina necesidad de establecer un persecución penal eficaz, que el legislador establece normas que, o regulan la actividad de recolección probatoria o la limitan, en términos tales, que si bien está reglada y autorizada la invasión del Estado a ciertos derechos ciudadanos en el procedimiento de persecución, estos casos deben estar circunscritos a aquellas situaciones, formas y relaciones de proporción que el legislador previó como tolerables.

\subsection{Criterios que debe tomar en cuenta el juez de garantía para autorizar la realización de tal diligencia}

El juez de garantía debe analizar si, en el caso concreto, resulta justificada la vulneración de garantías que implicaría la realización de la diligencia cuya autorización solicita el fiscal, atendida la gravedad o la importancia del hecho que se investiga ${ }^{15}$. En otras palabras, el juez debe aplicar el principio de proporcionalidad y operar con la lógica de costo versus beneficio, que lo inspira (ponderar, por un lado, la magnitud de la afectación de derechos que la diligencia importa y, por otro, la gravedad del hecho que se trata de esclarecer) ${ }^{16}$.

Además del principio de proporcionalidad, el juez de garantía debe examinar el mérito de la solicitud y la pertinencia de la diligencia que se pretende realizar. En otras palabras, debe analizar si hay antecedentes que permitan suponer la existencia del delito que se investiga y si la realización de la diligencia es necesaria para su esclarecimiento ${ }^{17}$.

Finalmente, el juez de garantía debe considerar en la ecuación la eventual afectación a la dignidad humana que la medida intrusiva puede acarrear, ya sea al imputado o a terceros. El propio legislador reconoce la existencia de este límite en la regulación de algunas diligencias intrusivas, al impedir, por ejemplo, la realización de exámenes corporales que puedan menoscabar la dignidad del interesado ${ }^{18}$. Por otro lado, la necesidad de respeto y preservación de la dignidad humana emana del propio texto constitucional, el que en su artículo $1^{\circ} \mathrm{le}$ otorga el carácter de digno a todo ser humano por el hecho de ser tal y fuerza, además, a supeditar los intereses del Estado (como lo es la persecución penal) al servicio del individuo.

\footnotetext{
15 Falcone y Oliver (2012), pp. 135-136.

16 Falcone y Oliver (2012), pp. 135-136.

17 Falcone y Oliver (2012), pp. 135-136.

18 Falcone y Oliver (2012), pp. 135-136.
} 


\section{Algunas diligencias limitativas de derechos fundamentales en el ordenamiento procesal penal}

En este apartado, nos proponemos destacar, aunque sea someramente, los aspectos legales y doctrinarios más relevantes de algunas diligencias limitativas de derechos fundamentales que han sido concretamente reguladas por el Código del ramo.

\subsection{Entrada y registro de inmuebles e incautación de objetos y documentos en el proceso penal chileno}

En este contexto, las medidas de entrada, registro e incautación son de aquellas medidas de investigación que requieren autorización judicial previa. Buscan, amén de la averiguación o comprobación de un hecho determinado, poder fijarlo de manera incontestable, de forma que lo obtenido a través de la diligencia pueda ser valorado como prueba en la etapa procesal de juicio ${ }^{19}$.

Por otro lado, como se puede apreciar, la medida de incautación se encuentra íntimamente relacionada con la de entrada y registro. Por tanto, es necesario detenerse brevemente y señalar algunas ideas sobre esta última.

La diligencia de entrada y registro persigue la obtención de fuentes de prueba para la comprobación del hecho punible o la participación culpable y/o para la solicitud de una medida cautelar. Se afecta la garantía constitucional de la intimidad e inviolabilidad del hogar (arts. $19 \mathrm{~N}^{\circ} 4$ y 5 CPR, 17 PIDCP, $11 \mathrm{CADH})^{20}$.

Sólo se exige autorización judicial previa para los lugares o edificios cerrados. Así las cosas, será necesario contar con la autorización judicial cuando el propietario o el encargado del edificio no permitiere la entrada y registro, debiendo el fiscal informar al juez sobre los motivos invocados por tales personas al negar la entrada y registro (artículo 205 inciso final CPP).

Excepcionalmente, la ley permite que la policía entre en un lugar cerrado y lo registre, sin el consentimiento expreso del propietario o encargado, cuando las

\footnotetext{
${ }^{19}$ En relación con diligencias de entrada, registro e incautación, se pueden revisar, entre otros, los siguientes trabajos: Álvarez y Rius (2009); Garay e Inchausti (2006); Martínez (2002); Moreira (2009), pp. 185-212; Palomo (2004), pp. 303 y ss.; Rives (2004); Roxin (1997), pp. 654-656; Zavidich (2009), pp. 147-156.

${ }^{20}$ La entrada y registro en derecho español es definida como: un acto procesal de investigación restrictivo de un derecho fundamental -la inviolabilidad del domicilio- condicionado a los presupuestos previstos en el ordenamiento jurídico, que tiene por objeto la penetración en un lugar para la detención del sospechoso, la ejecución de un mandamiento de prisión o para prevenir la comisión de un hecho delictivo y, en su caso, la observación, búsqueda y recogida de efectos o instrumentos del delito u otros objetos que puedan servir para su descubrimiento o comprobación cuando existan indicios determinantes para su adopción. Véase HiNojosa (1996), p. 55.
} 
Ilamadas de auxilio de personas que se encuentren en el interior u otros signos evidentes indiquen que en el recinto se está cometiendo un delito (artículo 206 inciso $1^{\circ} \mathrm{CPP}$ ). En este caso, la policía deberá comunicarse inmediatamente con el fiscal y levantar un acta del procedimiento cuya copia deberá entregarse al propietario o encargado del lugar, y la cual deberá ser remitida dentro de las 12 horas siguientes al fiscal (artículo 206 inciso $2^{\circ} \mathrm{CPP}$ ).

A efectos de hacer efectivas las correspondientes responsabilidades, la ley exige que quede constancia en los registros de la individualización del funcionario que practique el allanamiento, quien debe además procurar que la diligencia se desarrolle minimizando los daños y molestias a los ocupantes (artículo 205 inciso 2 CPP).

Por otro lado, la incautación es una medida intrusiva que afecta el derecho de propiedad del titular del bien respectivo, contemplado en el art. $19 \mathrm{~N}^{\circ} 24$ $\mathrm{CPR}^{21}$. En general, esta diligencia de investigación tiene por finalidad, tanto asegurar la evidencia que sirva para acreditar el cuerpo del delito y la participación culpable, como los efectos del respectivo delito, que puedan ser objeto de pena de comiso en la sentencia definitiva ${ }^{22}$.

Respecto del objeto de esta medida, en primer lugar, por documento se ha de entender cualquiera clase de escrito, sea carta, diploma u otros que den cuenta de un hecho; por lo que engloba diarios de vida, grabaciones y otros análogos, mientras que por correspondencia, se abarca un concepto más genérico de comunicación escrita, no limitándose a las epístolas, sino que comprendiendo la comunicación de ideas o sentimientos, llamadas telefónicas, fax o inclusive las encomiendas o paquetes postales. Ciertamente así se dejó establecido en la historia fidedigna del establecimiento de la garantía en comento, en que se entendió por comunicaciones privadas "todas aquellas en que el emitente singulariza al destinatario de su comunicación, [...] con el evidente propósito de que sólo él la reciba" ${ }^{23}$.

\footnotetext{
21 En este sentido véase Horvitz en HORVITZ y López (2002), p. 533.

22 Para algunos, la incautación conlleva un atentado al derecho a la intimidad (art. 19 № 4 de la CPR), en la medida en que afecta la esfera más privada de una persona y que aquélla desea mantener en reserva respecto de otras y que, en este sentido, puede ser denominado como una suerte de "autodeterminación informativa", toda vez que, a través de su protección, se permite a los ciudadanos decidir libre y soberanamente a quiénes, con qué grado de completitud, cómo y cuándo se dará una información y cómo se hará la divulgación de aquélla. Atañe también a la inviolabilidad de "toda forma de comunicación privada" (art. 19 № 5 CPR), entendiéndose como una manifestación del derecho anterior, aunque más concreta, y que tiene su fuente en la protección a la vida privada, ya que ella no se acaba en la persona humana, sino que reconoce en éstas la necesidad de establecer comunicaciones bien sea por la palabra hablada o escrita. De sólo cautelarse la vida privada y la honra se deja de lado la parte más social del ser humano y sin la cual la persona no logra su plena realización personal. Véase AcUÑa (2013), pp. 50 y ss.

${ }^{23}$ Actas Oficiales de la Comisión Constituyente, p. 340.
} 
Para determinar cómo se lleva adelante esta diligencia, se debe distinguir según si los objetos o documentos se encuentran en poder del imputado o de un tercero ${ }^{24}$ :

a) Si los objetos o documentos se encuentran en poder del imputado: puede ocurrir que quiera entregarlos voluntariamente, caso en el cual se procede sin más a su levantamiento. Si éste se niega a entregarlos o si el requerimiento de su entrega voluntaria puede poner en peligro el éxito de la investigación, la incautación sólo puede hacerse previa "orden" judicial (artículo 217 inciso $1^{\circ}$ CPP). Hacen excepción a la regla antedicha los casos de delitos flagrantes y de objetos o documentos que se encontraren en el sitio del suceso, pues en ellos la incautación cabe en forma inmediata, sin previa orden ni autorización judicial [artículos 83 letra b) y 187 inciso $2^{\circ} \mathrm{CPP}$ ].

b) Si los objetos o documentos se encuentran en poder de un tercero: éste puede, en primer término, hacer entrega voluntaria de los mismos. Si ello no sucediese, se le puede apercibir para que los entregue, del mismo modo como puede apremiarse a un testigo para que declare ante el Ministerio Público, es decir, mediante arresto o multa (artículo 217 inciso $2^{\circ} \mathrm{CPP}$ ).

También debemos señalar que existe un listado de objetos y documentos sobre los que no puede recaer la incautación (artículo 220 CPP). Por otro lado, el artículo 221 del CPP establece que de toda diligencia se levantará un inventario, conforme a las reglas generales. El encargado de la diligencia otorgará al imputado o a la persona que lo hubiere tenido en su poder un recibo detallado de los objetos y documentos incautados.

Al Ministerio Público corresponde la conservación bajo custodia de las especies recogidas durante la investigación, debiendo habilitar dependencias para tal fin y adoptar las medidas necesarias para evitar que se alteren de cualquier forma (artículo 188 CPP).

Este deber se relaciona con la llamada "cadena de custodia" de las fuentes de prueba, es decir, con los resguardos necesarios para la preservación de la evidencia hasta su presentación en juicio. Evidentemente, en una estructura procesal cuya pieza principal es el juicio oral, fase en que se produce la prueba que servirá de base a la sentencia, es fundamental la conservación de los objetos, documentos y especies de la investigación desde su levantamiento hasta su presentación a la audiencia principal del procedimiento. Para el Ministerio Público esta tarea es aún más relevante, pues tiene la carga de la prueba y debe superar el estándar de convicción "más allá de toda duda razonable" que fija el artículo 340 del CPP. Así las cosas, cualquier sospecha respecto de la indemnidad o integridad de la evidencia, o de su manejo inadecuado, pueden repercutir

${ }^{24}$ Falcone y Oliver (2012), pp. 139 y 149. 
negativamente en la presentación del caso. Cuando la falta de conservación de una especie afecte los derechos del imputado, éste podrá reclamar ante el juez de garantía a fin de que se adopten las medidas necesarias para la debida preservación e integridad de los objetos recogidos. La misma reclamación podría efectuarse por la víctima, el querellante o el actor civil ${ }^{25}$.

Cuando el imputado u otro interviniente deseen tener acceso a las especies incautadas con el fin de realizar alguna pericia o reconocimiento, deberán solicitar autorización al Ministerio Público o al juez de garantía, cuando aquél se niegue a la misma. El Ministerio Público deberá llevar un registro especial en el que consten la identificación de las personas autorizadas para reconocerlas o manipularlas. Esta norma constituye una cautela que permite reconstruir la cadena de prueba a fin de determinar las responsabilidades personales que pudieren existir respecto de manejo inadecuado o indebido ${ }^{26}$.

De acuerdo con el artículo 189 del CPP las reclamaciones o tercerías que los intervinientes o terceros entablen durante la investigación con el fin de obtener la restitución de los objetos recogidos o incautados se tramitarán ante el juez de garantía. Por otro lado, se establece que la resolución que la acoja se limitará a declarar el derecho del reclamante sobre dichos objetos, pero no se efectuará la devolución de éstos sino hasta después de concluido el procedimiento, a menos que el tribunal considere innecesaria su conservación ${ }^{27}$.

La excepción a esta regla la constituyen los efectos de algunos delitos contra la propiedad. En efecto, las cosas hurtadas, robadas o estafadas se entregarán a su dueño en cualquier estado del procedimiento, una vez comprobado su dominio por cualquier medio y establecido su valor.

La ley señala que deberá dejarse constancia mediante fotografías u otros medios que resulten convenientes de las especies restituidas o devueltas, las que podrán ser incorporadas como medio de prueba de conformidad con lo dispuesto en los artículos 323 y 333 del CPP.

\footnotetext{
${ }^{25}$ HorvitZ Y López (2002), pp. 536-537.

26 HORVITZ Y López (2002), p. 537.

27 Estos artículos se relacionan en parte con la llamada "responsabilidad civil ex-delicto". La comisión de un hecho delictivo no sólo puede comportar responsabilidad penal, sino también la denominada responsabilidad civil ex delicto. En efecto, responsabilidad penal y responsabilidad civil, pese a su distinta naturaleza, tienen, como presupuesto común, la concurrencia de un acto ilícito, es decir, un acto u omisión contrario a derecho: lesión o puesta en peligro de un bien jurídico y causación de un daño, respectivamente. Así, ilícito penal y civil forman parte de una categoría más amplia, los "actos ilícitos". Por tanto, no hay una diferencia cualitativa entre un ilícito penal y un ilícito civil, sólo una decisión político-criminal que ha llevado al legislador a la tipificación de ciertos ilícitos. Véase NúÑEZ y Pérez (2013), pp. 280-281.
} 


\subsection{Diligencia autónoma de la policía de control de identidad}

Por regla general, la policía no se encuentra facultada para interceptar personas y requerir su identificación, lo cual es una manifestación de la garantía constitucional de la libertad ambulatoria o de desplazamiento. Por excepción, el art. 85 CPP obliga a la policía a solicitar la identificación de cualquier persona en determinados $\operatorname{casos}^{28}$.

El control de identidad es una zona intermedia, pues se mueve entre dos extremos: el ejercicio de la libertad ambulatoria y las hipótesis de flagrancia delictiva, donde lo que procede es la detención del sujeto ${ }^{29}$.

Esta diligencia puede tener lugar en los casos fundados en que, según las circunstancias, los funcionarios policiales estimaren que existen indicios de que la persona controlada: a) Hubiere cometido o intentado cometer un crimen, simple delito o falta, b) Se dispusiere a cometerlo, c) Pudiere suministrar información útil para la indagación de un crimen, simple delito o falta, y d) Cuando la persona se encapuche o emboce para ocultar, dificultar o disimular su identidad.

\section{Consideraciones generales sobre la prueba ilícita}

\subsection{Control de las garantías durante la etapa de investigación}

Hemos afirmado que la investigación penal se trata de una actividad de índole administrativa, llevada adelante en términos generales por el Ministerio Público, órgano que por definición (artículo 83 inciso $1^{\circ}$ de la CPR) está vedado de ejercer funciones jurisdiccionales. Durante esta etapa preparatoria, no se adoptan decisiones relativas al fondo del conflicto penal y es por eso que la participación de la función jurisdiccional durante la etapa de investigación, sólo se limita a aspectos complementarios a esta última, como pueden ser las autorizaciones judiciales para medidas intrusivas (artículos 9 , 202, 218 del CPP, etc.), la concesión de medidas cautelares que aseguren el cumplimiento de los fines del proceso (artículos 140, 155 y 157 del CPP), la adopción de medidas idóneas para asegurar el ejercicio del derecho a defensa del imputado (artículos 10, 95, 186 del CPP, etc.).

Nuestro legislador ha previsto y reglado varios posibles casos de afectación de garantías esenciales durante la etapa investigativa. Así, se establecen diversas hipótesis bajo las cuales es posible para el Ministerio Público (o las policías) conculcar derechos esenciales, en la medida que se cumplan ciertos requisitos y presupuestos. El control sobre la correcta aplicación de la normativa del instituto

${ }^{28}$ Falcone Y Oliver (2012), p. 61.

${ }^{29}$ Falcone y Oliver (2012), p. 62. 
invocado sólo podrá ser revisada ex post por la instancia jurisdiccional respectiva. Se trata, a modo de ejemplo, de aquellos casos en que la ley ha reglado la detención por flagrancia (artículo 130 CPP), la realización de controles de identidad (artículo 85 CPP) o la entrada y registro de un inmueble "...cuando las llamadas de auxilio de personas que se encontraren en el interior u otros signos evidentes indicaren que en el recinto se está cometiendo un delito" (artículo 206 CPP), etc.

Por otra parte, existe un ilimitado catálogo de posibles diligencias conculcadoras de derechos esenciales, en las cuales, ora porque fácticamente es posible proceder mediante autorizaciones previas, ora porque son particularmente más violentas que las primeras, sólo puede procederse existiendo una autorización judicial anterior que la conceda. Algunos de estos casos de autorización judicial previa han sido reglados particularmente por el legislador, como sucede en las tomas de muestras corporales de un sujeto (artículo 197 CPP), la interceptación de las comunicaciones (artículo 222 CPP), etc. Para el resto de diligencias no expresamente regladas, catálogo por lo demás ilimitado, existe una cláusula amplia contenida en el CPP, en su artículo $9^{\circ}$, que reza que "toda actuación del procedimiento que privare al imputado o a un tercero del ejercicio de los derechos que la Constitución asegura, o lo restringiere o perturbare, requerirá de autorización judicial previa".

La reglamentación referida y el mecanismo establecido en ella, forman parte de un primer sistema de control de legalidad y constitucionalidad de las actuaciones investigativas, de una inspiración eminentemente preventiva, que buscan cuidar que la persecución se desarrolle en las condiciones que el legislador y el constituyente previeron, y sólo en aquellos casos en que lo establecieron.

\subsection{Reglas de exclusión de prueba y prueba ilícita}

Las medidas descritas supra, de carácter fundamentalmente preventivo, que adopta nuestra legislación y los ordenamientos comparados en general, serán en múltiples ocasiones insuficientes e ineficaces para proteger las garantías esenciales, ya sea porque no hubo control previo, porque si bien existiendo él mismo fue insuficiente o porque habiendo existido autorización previa, la ejecución la desborda. Generada que sea la prueba con la infracción de garantías, cualquier interviniente en el proceso, no obstante lo anterior, podría tener la expectativa que aquel medio sea introducido a juicio y valorado en el mismo. Para el problema planteado, cada sistema jurídico debe construir una respuesta para este dilema. Entre nosotros, son precisamente las reglas de exclusión y específicamente las de la prueba ilícita, aquellas que proporcionan soluciones para esta tipología de situaciones. 
Conviene precisar, como punto de partida, la íntima relación que la doctrina aprecia entre el respecto de las garantías fundamentales, la legitimidad del ejercicio jurisdiccional y el cognoscitivismo (conocer los hechos). Siguiendo a Ferrajoli, un sistema garantista debe construirse fundamentalmente, en lo que nos convoca, sobre aserciones sujetas a verificación, lo que se logra estableciendo "... un sistema de minimización del poder y de maximización del saber judicial, en cuanto condiciona la validez de las decisiones a la verdad, empírica y lógicamente controlable, de sus motivaciones" (Ferrajoli, 1989, p. 20). Toda información que conduzca a una mayor riqueza decisiva, generará razonamientos y motivaciones susceptibles de ser controladas, excluyendo a contrapelo la subjetividad del juzgador. Para el autor citado, el juicio penal generará garantías a los ciudadanos cuando se logre restringir la actividad juzgadora al reconocimiento de la norma aplicable y al conocimiento del derecho ${ }^{30}$. La aspiración última de un modelo probatorio apegado a la idea cognoscitivista, conforme sostiene Gascón Abellán, en último término es el ideal de conocer o reconstruir los hechos efectivamente acaecidos ${ }^{31}$.

La concepción probatoria referida supra, postula que el sistema procesal penal, como cualquier sistema que emita decisiones, debe ser alimentado por una amplia y nutricia gama de informaciones. En este contexto, para lograr no sólo una decisión, sino la mejor posible, debe procurarse que los datos que se incorporen a juicio, para ser considerados al momento de la adjudicación, sean lo más amplios que las técnicas investigativas lo permitan. Bajo este prisma, una concepción garantista de justicia y enfocada a la satisfacción de los justiciados, debe regirse por una regla general indiscutible: la de la inclusión probatoria. Todo dato o información que sirva para la resolución del caso debe llegar a juicio.

Los sistemas con aspiraciones garantistas establecen, por regla general, la libertad probatoria, directriz que, según señala Maier, dispone que salvo que exista una regla jurídica que ordene lo contrario, todo hecho (afirmación sobre un hecho) puede ser probado en juicio y esa prueba puede ser a través de cualquier medio ${ }^{32}$. Esta directriz es la que establece nuestro CPP en su artículo 295 cuando expresa "todos los hechos y circunstancias pertinentes para la adecuada solución del caso sometido a enjuiciamiento podrán ser probados por cualquier medio producido e incorporado en conformidad a la ley".

Bajo esta perspectiva, toda regla de exclusión de prueba es derechamente excepcional. Sin embargo, los ordenamientos jurídicos comparados y la doctrina

30 Ferrajoli (1989), pp. 35-37.

31 Gascón Abellán (s.f.), p. 4.

32 Maier (2011), p. 108. 
aceptan de forma más o menos uniforme ${ }^{33}$, la existencia de cortapisas mínimas para el ofrecimiento probatorio, dentro de las que destaca, por ejemplo, la posibilidad de expulsar prueba que resulte impertinente o notoriamente excesiva, todo ello, en defensa de la economía procesal y la celeridad de los juicios. Para los efectos de este trabajo, sólo nos interesa una regla de exclusión, a saber, la llamada prueba ilícita.

\subsection{Concepto de prueba ilícita}

La aproximación al concepto de prueba ilícita presenta diversas complejidades, las que se inauguran desde la propia voz "ilícita" que se utiliza para construir el concepto. Se trata, por cierto, de una fórmula verbal engañosa, si se entiende que la ilicitud tiene que ver con la contrariedad con la ley, pero a la vez se dota al instituto de un contenido que excede con creces una cuestión acerca de la mera legalidad. Por otro lado, la proliferación de este instituto en los ordenamientos comparados, sus distintas realidades normativas y el profuso trabajo doctrinario, han provocado que se expanda el contenido de este instituto de forma tal que bajo él pueden ser incorporados conceptos muy disímiles ${ }^{34}$. Al complejo panorama descrito, debe sumarse la no siempre unánime terminología utilizada para referirse a este instituto ${ }^{35}$.

En cualquiera de las concepciones referidas en la doctrina asoman al menos dos elementos comunes, que son generalmente aceptados por la doctrina y que resultan plenamente aplicables al sistema nacional, como se dirá en su oportunidad. En primer término, existe consenso en que la prueba ilícita y sus reglas son verdaderas limitaciones o cotos al ingreso de conocimiento para el juicio criminal y, como tales, constituyen limitaciones a la regla general de la inclusión probatoria. En segundo lugar, y desde la óptica del contenido material del instituto, se entiende por prueba ilícita a aquella obtenida con infracción de garantías constitucionales. A esa conclusión también llega Carocca, quien expresa que en "... la corriente predominante en doctrina extranjera... se ha limitado la existencia de una prueba ilícita a los supuestos de vulneración de

\footnotetext{
33 Sobre el tema ver: DamASKA (1997), pp. 12 y ss.

34 Véase MiRANDA (1999), pp. 17-20. El autor reseña y explica las concepciones que denomina "amplias" sobre la prueba ilícita, desarrollada por la doctrina.

35 Véase CAROCCA (1998), pp. 308-311. El autor repasa cinco conceptos (prohibiciones probatorias, prueba ilegal o irregular, prueba ilegítima, prueba viciada y prueba clandestina) que se han utilizado en doctrina para aludir a cuestiones parecidas o parcialmente coincidentes con la prueba ilícita, proponiendo empero una diferenciación entre los primeros y esta última. En el mismo sentido, véase Maturana y MOntero (2010), pp. 870-872 y Maier (2011), pp. 109-110.
} 
determinadas normas constitucionales esenciales, consagradoras de derechos fundamentales" (Carocca, 1998, p. 307) ${ }^{36}$.

Existen dos espacios temporales, si bien íntimamente vinculados, diferenciables entre sí, en los cuales puede producirse la ilegalidad de la prueba: durante la "irregular obtención... y [en la] irregular incorporación al proceso". (Cafferata, 1998, p. 17). Mientras que el primer período se refiere a la afectación de garantías durante la etapa investigativa y, específicamente, en los procedimientos de recolección de información; el segundo instante alude a la afectación de derechos que pueda generarse con la incorporación de un medio al juicio. El caso característico resulta ser la primera categoría, toda vez que es precisamente durante la etapa investigativa, donde generalmente se produce de manera más crítica la tensión entre el interés estatal de investigar y sancionar los delitos y los derechos fundamentales. Así, un allanamiento irregular sólo podrá generar que lo que ahí se obtenga sea considerado prueba ilícita. Sin embargo, existen supuestos también en que la adquisición del elemento probatorio no ha sido obtenido con infracción de garantías, pero sí podría afectarlas la incorporación del elemento al juicio. Piénsese, verbigracia, en los llamados testigos de contexto, que se refieren a los comportamientos históricos del imputado, no directamente vinculados con los hechos materia de la acusación, pero que guardarían alguna relación con los últimos, al describir hábitos, costumbres, ritualidades, etc. Podemos afirmar que, en principio, nada hay que infrinja garantías en la obtención de estos testimonios por parte del acusador, empero, las objeciones relativas a la vulneración de derechos constitucionales puede formularse y fundarse en su incorporación a juicio, por el peligro de prejuicio que los mismos conllevan.

\subsection{La prueba ilícita en el ordenamiento procesal penal chileno}

Nuestro legislador penal adjetivo, coherente con las directrices del nuevo CPP y los principios establecidos a propósito del juicio oral, establece abiertamente una concepción cognoscitivista de la prueba, a través de la permisión casi absoluta de incorporar a juicio toda aquella información, conste en el medio que conste, que permita arribar a una decisión respecto del caso. El artículo 295 del CPP consagra expresamente un sistema de prueba libre al disponer que "todos los hechos y circunstancias pertinentes para la adecuada solución del caso sometido a enjuiciamiento podrán ser probados por cualquier medio producido e incorporado en conformidad a la ley". A su turno, en relación a los mecanismos probatorios, el artículo 323 del citado Código vuelve sobre la idea

${ }^{36}$ En similar sentido, véase HORvitz y López (2002), p. 168; MINI (2005), p. 18. 
de que para probar basta "... cualquier medio apto para producir fe...". Todas estas declaraciones relativas a la libertad de prueba son tácitamente reiteradas en el artículo 276 del mismo cuerpo legal, que en su inciso final nos recuerda que las hipótesis de exclusión son taxativas y excepcionales, ya que aquellas pruebas que no se encuentren en estas categorías "... serán admitidas por el juez de garantía...".

Establecida que sea la regla general inclusiva en materia probatoria, corresponde abordar la temática relativa a sistema o mecanismo diseñado por el legislador para permitir ejercer este control sobre la licitud de la prueba.

La primera norma relativa al control de la licitud probatoria, fue diseñada para ser ejercida por el juez de garantía durante la audiencia de preparación de juicio oral ${ }^{37}$. Se lee en el artículo 276 del CPP, bajo el epígrafe "Exclusión de pruebas para el juicio oral" que "del mismo modo, el juez excluirá las pruebas que provinieren de actuaciones o diligencias que hubieren sido declaradas nulas y aquellas que hubieren sido obtenidas con inobservancia de garantías fundamentales".

La primera hipótesis que plantea la norma citada se circunscribe al caso de la declaración de nulidad, la que por mandato del artículo 159 del CPP se refiere a "... actuaciones o diligencias judiciales defectuosas del procedimiento...". Al depositarse la responsabilidad del desarrollo de la actividad investigativa sobre los hombros del Ministerio Público y no de los Tribunales de Justicia, los casos en que resulta procesalmente posible declarar la nulidad de una actuación investigativa, se reducen a situaciones excepcionalísimas y de ninguna o escasa aplicación en la práctica forense. Siguiendo a Hernández, existirían dos tipos de actuaciones judiciales posibles, susceptibles de ser anuladas: las audiencias y las resoluciones. Fundamentalmente, la posibilidad que en una audiencia se genere material de relevancia probatoria, se limita a dos casos: la recepción de prueba anticipada y la de declaración del imputado. Tratándose de resoluciones judiciales con efectos probatorios, es posible un resultado más sustancioso desde el punto de vista práctico, toda vez que esta vía, la nulidad procesal, constituiría el medio para impugnar autorizaciones u órdenes judiciales, viciadas en su génesis, que generaron material probatorio

\footnotetext{
37 Véase Horvitz y LóPEZ (2002), pp. 197-204; HeRNÁNDEZ (2005), p. 90. Nuestra doctrina no es unánime respecto a si corresponde también a los tribunales orales en lo penal el control sobre la licitud de la prueba ofrecida. Para López, razones normativas y de buen funcionamiento del sistema, le llevan a concluir que en dicha instancia no puede, en términos generales, controlarse la prueba ilícita, y que sólo corresponde proceder a recibir y valorar los medios que se hayan incluido en el auto de apertura. En cambio, para Hernández, la norma del artículo 276 del CPP cumple una función de prohibición general de valoración, la que no sólo tiene como destinatario los jueces de garantía, sino también los tribunales orales en lo penal.
} 
que aspira ser presentado y valorado en juicio. El mismo Hernández agrupa en cuatro categorías los posibles fundamentos de la nulidad procesal relativa a una resolución con efecto probatorio. A saber, se trata de autorizaciones u órdenes: a) legalmente improcedentes; b) casos en que las mismas son procedentes, pero no se cumplió algún trámite establecido por la ley; c) casos en que son concedidas siendo legalmente procedentes, pero se ha logrado la decisión judicial mediante engaño u error, $y \mathrm{~d}$ ) casos en que se otorga sin vicios legales formales ni de voluntad, pero materialmente, desde un punto de vista ex ante, se aprecia su concesión como arbitraria y carente de todo fundamento ${ }^{38}$.

Ya sea por la limitación relativa a que sólo son anulables las actuaciones judiciales o que dentro de ellas, en realidad, para que procedan se requiere que estemos en presencia de un caso de grosero irrespeto de la normativa expresa que regula a las autorizaciones y órdenes, se tratan estas hipótesis de situaciones, si bien no impensables, claramente marginales.

La segunda hipótesis de casos de exclusión que plantea la norma precitada, en la segunda parte del precepto, relativa a la expulsión de las pruebas que hubiesen sido obtenidas con vulneración de garantías fundamentales, constituye, en realidad, la hipótesis de mayor incidencia práctica por la amplitud de términos en que la misma ha sido concebida ${ }^{39}$. Se trata de la exclusión probatoria por ilicitud por antonomasia. Este control de admisibilidad probatoria realizado por el juez de garantía, permite sin más, ya no sólo cuestionar el proceder judicial, sino el del Ministerio Público durante la investigación. Por otro lado, la vasta aplicabilidad de este precepto en materia de control probatorio, se debe también a que las alegaciones relativas a la exclusión probatoria no están sujetas a mayores reglas formales que la oportunidad (audiencia de preparación de juicio oral), a diferencia de lo que sucede con las referidas nulidades.

Existe una tercera barrera de control de la licitud probatoria, que corresponde a la competencia de la Excma. Corte Suprema, en materia de conocimiento del recurso de nulidad, el que puede ser acogido, de conformidad a lo dispuesto en la letra a) del artículo 373 del CPP, cuando en cualquier etapa del procedimiento o en el pronunciamiento de la sentencia "... se hubieren infringido sustancialmente derechos o garantías asegurados por la Constitución o por los tratados internacionales ratificados por Chile que se encuentren vigentes...". Se

\footnotetext{
38 HeRnÁNDEZ (2005), pp. 44-48.

39 Véase Hernández (2005), p. 90. Para el autor la norma del artículo 276 del CPP constituye una prohibición general de valoración de prueba ilícita, con independencia de la ubicación sistemática de la norma o su alcance directo. Siguiendo a este autor, así, podría excluirse por ilicitud, no sólo la prueba obtenida con vulneración de garantías, sino también aquella que no teniendo un origen espurio, su incorporación a juicio conculcaría derechos esenciales.
} 
trata de una medida sui generis, por cuanto si bien corresponde a una revisión posterior a la realización del juicio o dictación de la sentencia que habría validado la prueba ilícita, tiene la potencialidad de generar un efecto profiláctico en el proceso, ya sea por la reconsideración del real valor probatorio de los elementos viciados por parte del nuevo tribunal no inhabilitado que conoce del caso, o bien, a través de la orden del Máximo Tribunal de excluir para el nuevo juicio, el o los antecedentes vulneradores de garantías esenciales. Esto último, se trata de una tendencia jurisprudencial asentada en la Excma. Corte Suprema, la que se fundamentaría en el artículo 386 del CPP, que dispone que acogido un recurso y ordenada que sea la realización de un nuevo juicio, el tribunal ad quem debe determinar "... el estado en que hubiere de quedar el procedimiento...", determinación que incluiría la fijación del o los medios que deberán ser considerados en la nueva audiencia ${ }^{40}$.

Las medidas descritas constituyen, amén de las facultades concedidas durante la investigación al juez de garantía, el bloque de mecanismos ideados por el legislador procesal penal para asegurarse que la prueba con la que se enjuicie a los ciudadanos, se someta a una exigencia mínima de respeto de las garantías de los derechos esenciales, ya sea aquellos prescritos en la Constitución, sea se trate de otros contemplados en los tratados internacionales vigentes que haya suscrito Chile.

\subsection{Excurso: diferenciación entre la mera ilicitud y la infracción de garantías fundamentales}

Anteriormente afirmamos que pese al panorama inicial que puede llevar a imprecisiones y confusiones, podía distinguirse la existencia de un común denominador que pervive en cada concepción que se expresa sobre la prueba ilícita, cual era la obtención de elementos de convicción mediante vulneración de garantías fundamentales. Es ese antecedente el que justifica el consecuente de exclusión probatoria, quizá la sanción procesal más severa prevista por el legislador ${ }^{41}$.

El bloque legal que regula la prueba ilícita en nuestro CPP, al menos en sus modalidades de mayor aplicación, a saber, los mecanismos de los artículos 276 y 373 letra a), definitivamente no hacen referencia a una mera contravención legal como presupuesto de la prueba ilícita. Los mecanismos de depuración de prueba por ilicitud se activan sólo cuando están en juego "garantías

\footnotetext{
${ }^{40}$ Véanse Corte Suprema, rol № 6305-2010, de 19 de octubre de 2010; Corte Suprema, rol № 23462013, de 3 de junio de 2013; Corte Suprema, rol № 21413-2014, de 22 de septiembre de 2014, etc.

${ }^{41}$ En similar sentido, véase NúÑEz (2001), I p. 334.
} 
fundamentales" o "... derechos o garantías asegurados por la Constitución o por los tratados internacionales ratificados por Chile que se encuentren vigentes...", según corresponda ${ }^{42}$. El CPP ha establecido una categoría de infracción que no resulta equivalente a la mera ilicitud. Por cierto que la inobservancia de garantías fundamentales contenidas en la CPR, se encuentra en vinculación íntima a la infracción de ley. No se pretende en este excurso negar las evidentes vinculaciones entrambas, sino sólo insistir en su diferente nomenclatura.

Puede afirmarse que en la generalidad de los casos la existencia una vulneración a las garantías fundamentales llevará aparejada paralelamente también una infracción legal. Ello es así, porque tanto los tratados internacionales como la CPR establecen derechos fundamentales, los que normalmente son explayados y desarrollados por el ordenamiento de carácter legal. Así, el policía que, actuando sin autorización judicial ni hipótesis legal que lo autorice a proceder sin ella (autorización del afectado, signos evidentes que en el recinto se comete un delito, etc.), ingresa a un domicilio con el objeto de revisar la existencia de un elemento relevante para sus pesquisas, no sólo atenta contra la garantía de la inviolabilidad del hogar consagrada en el artículo $19 \mathrm{~N}^{\circ} 5$ de la CPR, sino también infracciona los artículos 9० $9^{\circ}, 205$ y 206 del CPP, preceptos que regulan el allanamiento de moradas, los que, salvo los casos excepcionales previstos por la ley, deben ser autorizados por el juez de garantía.

Sin embargo, es posible también concebir, aunque excepcionalmente, la existencia de estas categorías de infracciones de forma separada. En efecto, piénsese si durante la ejecución de un registro realizado con autorización judicial, son incautadas evidencias pertenecientes al propietario del recinto, consignando ello en los informes policiales, pero ignorando el otorgamiento del recibo a que hace referencia el artículo 216 del CPP. Resulta evidente que la falta de entrega del aludido recibo implica haber quebrantado una orden legal expresa. Sin embargo, parece no existir una afectación injustificada de la propiedad, toda vez que la misma ha sido perturbada al titular en un caso y de la forma prevista en el ordenamiento jurídico. La norma quebrantada, más bien, dice relación con aspectos de publicidad o de certeza para el afectado.

\footnotetext{
${ }^{42}$ Nótese que la nulidad procesal, instituto en el cual no se pretende ahondar en este trabajo, por mandato del artículo 159 del CPP exige para su procedencia la existencia de un perjuicio, el que el propio precepto define como un atentado a la posibilidad de actuación de cualquier interviniente, lo que en definitiva no es sino equivalente a afirmar que se haya infraccionado, en lo pertinente, el derecho de defensa. Por ello, y siendo este último derecho también una garantía fundamental, puede afirmarse que el instituto de la nulidad procesal, al igual que los otros dos mecanismos de control de prueba ilícita, es un instrumento paliativo de vulneración de garantías esenciales y no meras infracciones de ley.
} 
No aparece posible -no al menos de forma inmediata y natural- conectar la infracción legal con algún derecho fundamental.

También puede presentarse la hipótesis contraria. Un acto podrá ser completamente legal, sin embargo, poseer la potencialidad de perturbar derechos esenciales. A modo de ejemplo, considérese un caso en que un contribuyente, conforme al artículo 34 del Código Tributario, es citado a declarar de forma obligatoria y bajo juramento como compele la aludida norma. El contenido de una declaración prestada en esas condiciones, si intenta ser introducido en sede penal, puede razonablemente ser impugnado, por afectar el derecho a guardar silencio que tanto la CPR (vía garantía del debido proceso) y los tratados internacionales consagran.

En el sentido ya expuesto, Hernández ha declarado que "resulta forzoso concluir que la inobservancia de garantías fundamentales representa algo más que la mera inobservancia de la legalidad ordinaria, de suerte que para afirmarla no puede bastar con la infracción de ley en la obtención de la prueba, sino que además se requiere que la infracción pueda vincularse de modo tal con una garantía fundamental que pueda conceptualizarse como una afectación de la misma...". (Hernández, 2005, pp. 51 y 52). En el mismo orden de ideas, afirma González que "... la prueba ilícita no es una prueba que infrinja la mera ilegalidad ordinaria, ya que no toda ella está compuesta por garantías fundamentales... allí donde se infrinja una garantía fundamental, con independencia de la jerarquía constitucional o legal del precepto que la contemple o desarrolle, habrá también prueba ilícita". (González, 2010, p. 360).

Se trata también, dicho sea de paso, de la posición asumida por la Excma. Corte Suprema, la que ha sostenido -en las ocasiones donde más claramente ha podido pronunciarse sobre el tópico- que una vulneración de una norma legal no acarrea por sí sola la nulidad de un juicio o de una sentencia. Señala el Máximo Tribunal que sólo procede considerarse como concurrente la causal del artículo 373 a) del CPP cuando existe una garantía fundamental comprometida, siempre que, además, la afectación tenga un carácter de sustancial, en contraposición a lo que puede estimarse como sólo una afectación teórica de un derecho ${ }^{43}$.

\subsection{Principales fundamentos doctrinarios para justificar la exclusión probatoria por ilicitud}

En este apartado repasaremos brevemente las principales fundamentaciones que a nivel doctrinario se han impuesto para justificar la exclusión probatoria

${ }^{43}$ Véase Corte Suprema, rol № 5898-08, de 26 de enero de 2009; y Corte Suprema, rol № 3657-2010, de 23 de agosto de 2010. 
por ilicitud y que resultan aplicables al ordenamiento chileno. Sin temor a exagerar, podemos afirmar que se trata de una de las interrogantes más relevantes que pueden plantearse en razón de la temática en estudio, toda vez que sólo el comprender la razón de ser de este instituto y su sentido, permitirá fijar sus fronteras y resolver la casuística inagotable que presenta el diario quehacer investigativo y procesal ${ }^{44}$. Por otro lado, más allá de las finalidades pragmáticas, existe una razón sustantiva y de fondo para estudiar este fenómeno y consiste básicamente en fundamentar, si se quiere, en aras de la legitimidad del sistema de justicia, la exclusión de un material en principio valioso para resolver el caso. Ello, porque resulta en principio contrario al sentido común, prescindir de una información que aparece como necesaria y útil para resolver el conflicto. Existirán muchos casos en que el material probatorio recabado con vulneración de garantías fundamentales podrá ser absolutamente necesario para conocer los hechos y resolverlos adecuadamente. ¿Cuán necesaria, por cierto, es la referencia al arma homicida encontrada (en un allanamiento irregular) en el domicilio del imputado? En todos estos casos, cada vez que se expulsa prueba del proceso, lo que existe es una afirmación del ordenamiento jurídico, sin ambages, que subyace en el sistema algo más valioso que el conocer los hechos de la forma más acabada posible.

El profesor Julián López, con gran claridad didáctica, ha sistematizado en tres grandes grupos los fundamentos que justifican la exclusión probatoria por ilicitud. Se trata de los criterios de confiabilidad de la evidencia, de la integridad judicial y el de la prevención o deterrence ${ }^{45}$. Sin embargo, no debe perderse de vista que estas categorías no son excluyentes de otros muchos esfuerzos doctrinales que intentan avanzar hacia una justificación y un sentido de la exclusión ${ }^{46}$.

El criterio de la confiabilidad de la evidencia, siguiendo a López, postula que la prueba ilícitamente obtenida, proporciona un material probatorio defectuoso, de precaria calidad y de dudosa credibilidad ${ }^{47}$. No se cuestiona en esta línea argumentativa ni la ética estatal ni la moralidad de los agentes de persecución, se trata tan sólo de la afirmación que la prueba obtenida con violación de

\footnotetext{
${ }^{44}$ En el mismo sentido, véase Guariglia (2005), pp. 37-38. El autor sostiene que sólo es posible aproximarse a las prohibiciones probatorias, contando con un marco teórico definido, que considere el telos del instituto. De lo contrario, la prueba ilícita y su alcance quedaría entregada al completo arbitrio y discrecionalidad del intérprete, conforme determine para cada caso que conozca.

45 Horvitz y López (2002), pp. 180-187.

46 Véase Maturana y Montero (2010), pp. 877-882; Guariglia (2005), pp. 37-102, y Carocca (1998), pp. 315-318. Los autores citados exponen un amplio panorama de las tesis y argumentos doctrinales que justifican la exclusión de la prueba ilícita en el proceso penal y la prescindencia de todo valor probatorio de éstas.

47 Horvitz y López (2002), pp. 181-182.
} 
garantías no es fiable. La confesión arrancada a un sujeto mediante tortura física o apremios psicológicos intensos, es altamente probable que sólo obedezca al deseo del justiciado de poner fin a su sufrimiento y no necesariamente a la real ocurrencia de los sucesos que afirme.

Esta tesis puede ser objeto de múltiples críticas. En principio, ha sido desechada por su exceso de pragmatismo y desaprensión con el obvio dilema ético que la prueba ilícita conlleva, todo lo que en definitiva tributa a la legitimidad del sistema de justicia. Con el actual nivel de consenso que genera el respeto a los derechos fundamentales en las democracias occidentales, sencillamente, no es posible desatender el contenido moral del conflicto. Por otro lado, la afirmación relativa a la falta de fiabilidad de la prueba ilícita se trata de un aserto completamente cuestionable y sólo efectivo para un grupo acotado de casos. La prueba ilícita, en muchas ocasiones, independiente de su origen espurio, entrega material completamente verídico y contundente. Un allanamiento irregular, sin causa legal que lo autorice, practicado en un inmueble donde se encuentra gran cantidad de sustancias estupefacientes, que ha sido registrado en imágenes y perfectamente documentado, podrá generar prueba muy sólida y convincente en relación con la ocurrencia del delito y también de la participación de un sujeto en éste. Por último, como apunta Guariglia, en un sistema de libre valoración de prueba, no es posible declarar inadmisible un medio por su supuesto escaso valor, toda vez que ello en definitiva es un problema de apreciación del tribunal Ilamado a conocer del caso ${ }^{48}$.

En un segundo orden de ideas, siguiendo la sistematización de López, se encuentra el Ilamado criterio de la integridad judicial ${ }^{49}$. Se sostiene que, prescindiendo de aspectos relativos a la verdad material, el intríngulis de este asunto no es el hecho que el medio tenga alta o baja potencialidad de generar convicción. Lo relevante y lo que se juega en la prueba ilícita es la preservación de una ética jurisdiccional, que asegure que el Estado cuando persiga un delito mantendrá un comportamiento intachable, si se quiere, las manos limpias y que no incurrirá -a pretexto de "hacer justicia" - en comportamientos similares a los que pretende reprimir. Se trata de una reserva moral mínima, que constituye un verdadero compromiso estatal en el sentido que el derecho penal no será aplicado al costo que fuere ${ }^{50}$. Conforme sostiene Hernández, se trata del criterio que se ha impuesto en el sistema alemán, el cual reconoce

\footnotetext{
${ }^{48}$ Guariglia (2005), p. 41.

49 Horvitz y López (2002), pp. 183-185.

${ }^{50}$ Véase en similar sentido KRAuSE (2005), p. 15. Para la autora, a final de cuentas, la consagración de la prueba ilícita y; en definitiva, de la puesta de límites a la actividad probatoria, es un indicador de la existencia de una organización democrática estatal, toda vez que es un reconocimiento a que el ser
} 
“... la supremacía de ciertos valores ideales por sobre las necesidades prácticas de la persecución penal" ${ }^{\prime 51}$.

Finalmente, explica López, existe el Ilamado criterio de la prevención o deterrence, sistematización desarrollada y defendida principalmente por la jurisprudencia norteamericana ${ }^{52}$. La fundamentación de la prueba ilícita se encontraría en la necesidad de disciplinar a las policías (y organismos de persecución penal). La exclusión probatoria contendría así un mensaje claro y categórico a los agentes policiales: nada de lo que recaben o hagan vulnerando derechos esenciales servirá como prueba en juicio. Todo el material que produzcan vulnerando garantías será desechado y no es más que una pérdida de tiempo y de recursos el proceder violando garantías. Por ende, tendría la finalidad de enseñar a las policías sobre el correcto proceder, desincentivando, en contrapartida, los comportamientos antinormativos.

\subsection{Posición de los autores respecto de la fundamentación de la prueba ilícita en el derecho procesal penal chileno}

Variados autores de la doctrina nacional han sostenido que el solo texto de la Carta Fundamental, sin necesidad de recurrir a la normativa del CPP, permitiría justificar la existencia del fenómeno de la exclusión probatoria por ilicitud ${ }^{53}$. Ello se sostiene en la supremacía de la CPR y, por sobre todo, en la sustancialidad de los derechos por ella consagrados. Siguiendo a Aldunate, al hablar de derechos fundamentales pensamos en aquellos que "... junto con considerarse naturales o innatos, tienen un carácter primario o básico; su carácter fundamental alude a su importancia o trascendencia para el desarrollo de la persona" (Aldunate, 2008, p. 48). Nuestra CPR, en su artículo $5^{\circ}$, dispone que la soberanía, de la cual la jurisdicción es su desprendimiento, reconoce como límite el respeto de los derechos esenciales. Por lo anterior, el ejercicio de la jurisdicción sólo podrá ser legítimo con la condición y en la medida que se respeten los derechos inherentes a la dignidad humana. Los artículos 276 y 373 a) del CPP, no hacen sino velar porque el ejercicio del ius puniendi respete la limitación impuesta por la propia Constitución. La exclusión probatoria por ilicitud y los derechos fundamentales están unidos de forma indisociable en una relación de medio a fin ${ }^{54}$.

humano no está al servicio de la persecución penal y ésta, si el Estado decide llevarla a cabo, debe efectuarse conforme al catálogo de derechos y garantías que se reconocen a toda persona.

51 HeRnÁNDEZ (2005), p. 28.

52 Horvitz y LÓPEZ (2002), pp. 186-187.

53 Véase Zapata (2004), pp. 46-55; Bofill (1988), p. 243, y ECheVerRía (2010), p. 107.

54 En similar sentido, véase HeRnÁndez (2005), p. 61. 
Los derechos fundamentales, independientemente que estén consagrados de forma positiva y tengan fuerza coactiva, son normas dotadas de un profundo e innegable contenido ético. Ellas representan un compromiso, en lo que nos interesa, en torno a que el Estado en el ejercicio de la justicia penal no renunciará a aquello que se comprometió a defender: los derechos fundamentales.

Lo que hasta aquí se ha señalado, no es sino el reconocimiento que en nuestro sistema rige como fundamento principal de la prueba ilícita, la llamada integridad judicial. El Estado sancionador sólo podrá "jugar" respetando las reglas existentes y principalmente aquella ética mínima que dice relación con la preservación de la dignidad humana ${ }^{55}$. Aquella también ha sido la conclusión a la que ha llegado Hernández, para quien "... el fundamento de la exclusión de la prueba ilícita en el proceso penal es uno esencialmente ético... y está referido a la legitimidad de la acción estatal. El ejercicio del poder punitivo del Estado sólo puede legitimarse en el escrupuloso respeto de las garantías penales y procesal-penales de los ciudadanos; en caso contrario, toda imposición de una pena no es más que un ejercicio de violencia despótica, carente de toda posible justificación". (Hernández, 2005, pp. 60-61).

Expresado lo anterior, corresponde señalar que la necesidad de disciplinar el actuar policial, si bien no resulta ser el fundamento principal del instituto en estudio, es admisible como una finalidad secundaria perseguida por el legislador. Ambos fines y objetivos de la prueba ilícita, resultan perfectamente armonizables en su convivencia, conforme sostiene López, toda vez que operan en planos diversos (ética versus eficiencia) ${ }^{56}$. Ambos también, en opinión de estos autores, fueron tenidos en consideración en el nuevo $\mathrm{CPP}^{57}$.

\subsection{Morigeraciones a la regla de exclusión de prueba ilícita. Principio de proporcionalidad}

La doctrina chilena, recogiendo principios y conceptos desarrollados en el derecho comparado, tiende a aceptar que la expulsión de la prueba ilícita del proceso puede reconocer morigeraciones o excepciones. Se habla y se acepta generalmente como reglas de excepción a la expulsión probatoria, las

\footnotetext{
55 En similar sentido, véase BofiLl (1988), p. 242.

56 HORVITZ Y LÓPEZ (2002), p. 187.

57 En el Mensaje del Ejecutivo al Legislativo, con el cual se remite el Proyecto de CPP, se expresa que "el cambio político más importante en Chile ha sido, a su turno, la consolidación del modelo democrático, el que a su vez exige el respeto a los derechos humanos como un principio fundamental de legitimidad". Por otro lado, se expresa que se persigue con este nuevo cuerpo legal "... cambiar fundamentalmente el modo en que los tribunales desarrollan el procedimiento penal, proyectando ese cambio hacia el trabajo de los organismos policiales...".
} 
concepciones denominadas como de buena fe, de la fuente independiente, del descubrimiento inevitable, del vínculo atenuado, etc. ${ }^{58}$. Ninguna de ellas, por cierto, tienen reconocimiento en el texto positivo; sin embargo, gozan de considerable aceptación por razones cuya exposición excede al objetivo de este trabajo.

Lo que pretende destacarse con lo anterior, es que goza de aceptable consenso doctrinario la existencia de una cierta relatividad de las reglas de exclusión, o si se quiere, la negación de un efecto absoluto de éstas. Lo anterior, estimamos, se motiva en el hecho que las reglas de exclusión probatoria por ilicitud $-y$ las chilenas en concreto- constituyen un nudo donde pueden colisionar y anularse, suprimirse o menguarse, distintos derechos fundamentales e intereses constitucionalmente legítimos. Los conflictos en materia probatoria estarán representados, por un lado, por los derechos esenciales amagados (la propiedad de quien vio incautada su especie, la intimidad de quien sufrió la irrupción policial en su hogar, etc.) y, por otro, el interés estatal en la persecución penal, al que aluden diversas normas constitucionales y es, por cierto, pilar básico de una sociedad mínimamente organizada ${ }^{59}$.

Frente a esta problemática, surge la necesidad de establecer un mecanismo metodológico que supere las limitaciones de los clásicos análisis binarios e introduzca criterios no sólo de validez, sino también de medida. Nos referimos a la llamada doctrina de la ponderación o principio de la proporcionalidad, el que estimamos posee bases doctrinarias y positivas para ser aplicado en Chile.

El punto de partida de esta propuesta pasa por aceptar que los derechos fundamentales, en el complejo entramado que genera la convivencia social, son susceptibles, en palabras de Hernández, de modulación. Para él "un fundamento ético o valorativo no supone, como es evidente, que lo así fundado tenga un carácter absoluto y no susceptible de modulaciones, sino que al contrario sugiere la necesidad de ponderar los valores en juego" ${ }^{\prime 60}$.

Esta propuesta dogmática ha sido expuesta originalmente por el autor alemán Robert Alexy. Para el referido autor, la ponderación es una metodología que permite solucionar conflictos entre principios. Los principios son normas que prima facie aparecen como aplicables igualmente a un caso, pero a la vez incompatibles entre sí. Los principios, a diferencia de las reglas, no contienen órdenes perentorias ni soluciones concretas para casos específicos. Se tratan en realidad de "mandatos de optimización", los que consisten en la orden que algo sea realizado en la mayor y mejor medida posible. Este ejercicio exige

${ }^{58}$ Véase Hernández (2005), pp. 59-84; Zapata (2004), pp. 31-35, y Basso (2013), pp. 36-38.

59 Arts. $19 \mathrm{~N}^{\circ} 7$ y 80 de la CPR, entre otros.

${ }^{60}$ Hernández (2005), p. 63. 
confrontar el principio con aquellos que le resultan contrapuestos y, hecho ello, podrá determinarse cuál de los dos resulta preferente para solucionar el caso. Admiten por ello un cumplimiento gradual. Las reglas, en cambio, sólo admiten ser cumplidas o no cumplidas, no pudiendo satisfacerse en grados ${ }^{61}$. Se trata, como puede observarse, de un ejercicio que renuncia a intentar fórmulas de soluciones universales, construyéndose respuestas sólo para el caso en concreto que se trata de solucionar.

La ponderación, explica Bernal, contempla efectuar una serie de consideraciones, las que pasan, entre otras, por determinar el grado de certeza con que puede preverse que se afectarán los principios involucrados (la mera probabilidad tendría un peso específico menor frente a la certeza); la importancia social que tiene cada uno de los principios en contraposición; la necesidad de satisfacción de cada uno de ellos; el grado de afectación que puede preverse que los mismos sufrirán, etc. ${ }^{62}$.

En nuestro sistema, resulta plenamente aplicable esta metodología de solución de conflictos normativos. Como ya se ha dicho, a pesar de que el tenor del artículo 276 inciso $3^{\circ}$ del CPP pareciera no admitir matices, tal como ha sostenido Hernández, el texto positivo es sólo el punto de partida del análisis ${ }^{63}$. Tratándose de preceptos que regulan la vigencia de las garantías esenciales e intereses salvaguardados por la Constitución, los que no se anulan entre sí, se requiere asegurar la debida coexistencia de los mismos y su interrelación armoniosa. Para ello, la modulación o fijación de los límites de los mismos resulta un ejercicio ineludible.

Si la propia naturaleza de este conflicto reglado por la norma se estimara como insuficiente argumento para determinar la necesidad de la ponderación, debe tenerse en cuenta además que esta última ha sido expresamente consagrada por el legislador, a raíz del recurso de nulidad, conforme se lee en el artículo 373 a) del CPP. Dicha norma mandata que no será cualquier infracción a las garantías básicas suficiente para anular un juicio o una sentencia. La nulidad sólo procederá cuando ocurra una infracción de carácter sustancial. Lo anterior, por descarte, deja fuera del ámbito de la nulidad todo tipo de infracciones que puedan estimarse de una menor entidad o de una mínima relevancia.

Así las cosas, las dos últimas normas precitadas, fuentes principales de la regulación de la prueba ilícita en nuestro ordenamiento, permiten la introducción

\footnotetext{
${ }^{61}$ AleXy (1986), pp. 82-114.

62 Bernal (1989), pp. 8-28.

63 Hernández (2005), p. 60.
} 
de la ponderación como un mecanismo legítimo de resolución de conflictos de normas iusfundamentales y de intereses constitucionalmente protegidos ${ }^{64}$.

Por otro lado, la mecánica relativa a la ponderación de los derechos e intereses en juego, no es una metodología que pretenda utilizarse injertándose como un cuerpo ajeno a nuestro sistema jurídico, sin base alguna. Numerosos preceptos del CPP Ilaman al juez a realizar exámenes comparativos entre valores y/o derechos en juego y exigen la realización de juicios de proporcionalidad, entre la afectación de las garantías y los intereses que se privilegian. Se distinguen generalmente estas normas por la referencia positiva a la gravedad del caso, a su carácter calificado o a la necesidad o indispensabilidad de algo ${ }^{65}$.

A nivel jurisprudencial, la Excma. Corte Suprema, en diversos y continuos fallos, ha manifestado que la existencia de una infracción de garantía no significa ipso facto que deba anularse un juicio o sentencia, debiendo siempre hacerse una ponderación relativa a la trascendencia del perjuicio que se alega. Este análisis no es sino un Ilamado a determinar la entidad y gravedad del principio parcialmente sacrificado y la relevancia de aquel que se ha privilegiado ${ }^{66}$. ${ }^{64}$ A favor de la aplicabilidad de la ponderación en el derecho chileno, véase HERNÁNDEZ (2005), p. 63;
López en HORVITZ y LóPEZ (2002), pp. 175-178. En contrario, véase ECHEVERRíA (2010), pp. 43-44. Para
esta última autora, el artículo 276 del CPP funciona como una regla, en lo que dice relación a la prueba
de cargo. Por ello, para esta autora, producida que sea una vulneración a una garantía fundamental, no
es necesario chequear principio contrapuesto alguno, sino que debe producirse sin más la exclusión
de la prueba de cargo.

65 Artículos 140, 222, 457 del CPP, entre otros.

${ }^{66}$ Véase, Corte Suprema, rol № 2576-2011, de 11 de mayo de 2011. En la misma, el Máximo Tribunal se pronuncia expresamente sobre las limitaciones a la exclusión probatoria manifestando que "en nuestro Código Procesal Penal no se establecen expresas normas sobre este tema, pero parece necesario tener presente que el principio de la proscripción de la prueba ilícita reconoce limitaciones...". Luego, dicho fallo, expresa que "lo que aparece claro es que la existencia de una prueba ilícita no significa directa e inmediatamente la nulidad de una actuación, sino que es preciso traspasar primero, el cedazo de la preparación y, luego, el de la trascendencia que el legislador nacional impuso en el artículo 373 letra a) del Código Procesal Penal, sin descuidar tampoco el sistema de valoración probatorio y la disposición constitucional del artículo 19 No $^{\circ} 26$ que impone a todos los ciudadanos la obligación de 'tolerar' ciertas restricciones en sus derechos, en tanto no se vulnere el núcleo esencial del mismo". Con lo anterior, la Excma. Corte Suprema, se manifiesta en favor de considerar la exclusión probatoria como un principio y no como una regla, siendo por ello necesario, en cada infracción a garantías que se invoque, proceder a realizar un juicio de ponderación. Véase también, Corte Suprema, rol No 1741-2010, de 25 de mayo de 2010. Allí, la Excma. Corte Suprema expresa la idea que "... las reglas de exclusión de pruebas no se aplican en forma absoluta y reconocen varios límites, asentados en criterios desarrollados fundamentalmente por la jurisprudencia de la Suprema Corte de los Estados Unidos de América...". Por otro lado, se asegura en el fallo que la legitimidad del procedimiento y la vigencia del estado de derecho, no pueden fundarse en la intangibilidad de las garantías básicas sino en la existencia de "... una regulación que las limite a los casos y a la medida en que sean realmente indispensables...". En este fallo, la Excma. Corte Suprema reconoce abiertamente que frente a la necesaria fricción que se producen entre derechos o garantías básicos y la persecución 


\section{Algunos problemas relativos a las medidas intrusivas y la prueba ilícita}

En este apartado nos detendremos en ciertas categorías casuísticas en relación con las medidas intrusivas tratadas, las cuales se presentan de forma más o menos cotidiana en los procesos investigativos, las que serán analizadas desde la perspectiva de la prueba ilícita. Dejaremos fuera de estudio aquellos casos de infracción de garantías palmarias o evidentes, como podría ser la no obtención de autorización judicial, en una hipótesis en que expresamente se la requiere. Nuestra atención se centrará en algunos de los llamados "casos difíciles", situados muchas veces en fronteras imprecisas y difusas.

\subsection{Autorización viciada del imputado o del afectado por la medida}

Tanto el allanamiento de un inmueble, como la incautación de especies, son diligencias que pueden ser válidamente realizadas, en términos generales, si se cuenta con la autorización del afectado por la medida (artículos 205 inciso $1^{\circ}$ y 217 inciso $1^{\circ}$, ambos del CPP). Mediante ambas disposiciones el legislador "renuncia" a la protección del derecho a la inviolabilidad del hogar, de la privacidad y la propiedad (artículo $19 \mathrm{~N}^{\circ} \mathrm{s} .4^{\circ}, 5^{\circ}$ y 24 de la CPR), en aquellos casos en que se cuenta con la anuencia del afectado. Esta autorización, como sea, o bien habilita para la vulneración legítima de la garantía esencial o, en su defecto, podemos entender que la hace desaparecer, ya que el acto voluntario recaería sobre una esfera de derechos en principio disponible.

Si bien es cierto las reflexiones que puedan realizarse en torno al consentimiento, en muchos aspectos, resultan válidas tanto para la medida de entrada y registro de un lugar cerrado como para la incautación de especies, revisaremos, en especial, la situación de la primera medida señalada.

No obstante ser el consentimiento la línea divisoria entre una legítima medida intrusiva investigativa y una violación estatal de derechos fundamentales y ergo, lo que separa aguas entre la prueba admisible y aquella considerada ilícita, no se le ha dedicado a éste mayor atención por nuestro legislador procesal penal. Lo peligroso de la omisión, huelga señalarlo, es que el control judicial tienda a asentarse en una simplificación meramente formal, en términos tales que sea considerada legítima la medida que aparezca respaldada por una rúbrica

penal, el juicio de legitimidad de la afectación pasa por la determinación de la necesidad de la medida y su proporcionalidad con los derechos que amaga. Véanse también, entre otros, Corte Suprema, rol № 10910-13, de 7 de enero de 2014; Corte Suprema, rol № 3912-11, de 19 de julio de 2011; Corte Suprema, rol № 14784-14, de 4 de agosto de 2014. En ellas, el Máximo Tribunal desarrolla la tesis relativa al principio de trascendencia o perjuicio necesario en toda nulidad, en virtud del cual funda la distinción (implícita) entre afectaciones sustanciales a las garantías y otras que no producen perjuicio alguno, o no al menos de forma relevante. 
del afectado o por alguna mención ritual en las actas policiales, mientras que ilegítima la que no encuentre su respaldo en tales evidencias ${ }^{67}$. La tentación de aceptar esta caricaturización del problema, radica en la relevante dificultad probatoria que puede implicar el acreditar sucesos generalmente probados en ambientes protegidos o de accesos restringidos y, por otro lado, conectados con el fuero interno de un ciudadano. La ausencia de fallos de los Tribunales Superiores de Justicia referidos al tema y la prácticamente nula referencia doctrinal sobre él mismo, ya avisan que hemos preferido la realización de un análisis puramente formal del consentimiento, sin detenernos mayormente aún en la calidad del mismo.

Sin embargo, asumir la responsabilidad de una aplicación efectiva de las garantías constitucionales y la subordinación del poder coercitivo del Estado a los derechos esenciales, demanda no conformarse con una evaluación de las formas sino avanzar hacia la elaboración de un estándar que considere aspectos cualitativos relacionados con el grado de información y de libertad con que se construyó el consentimiento.

Bien pueden, fundadamente, objetarse las circunstancias en que se concedió la autorización por el afectado, arguyendo la existencia de una presión indebida, de una amenaza velada o la tergiversación de los antecedentes que la rodean o justifican. Es posible concebir que por un excesivo entusiasmo de los agentes de investigación, su premura, mala fe, u otra causa, el afectado con la medida que renuncia a su garantía, no llegue a entender nunca cabalmente su desprendimiento y la posibilidad que tiene de negarse al requerimiento.

El caso aumenta sustantivamente su complejidad, cuando la autorización es otorgada por un imputado detenido - quien goza, por tanto, de todos los derechos que le asisten además en su calidad de tal-, el cual es trasladado hasta su hogar y allí "consiente" en el ingreso al mismo por parte de la policía ${ }^{68}$. El sujeto detenido se encuentra en una ostensible situación de subordinación de

\footnotetext{
${ }^{67}$ Véase MAIER (1989), p. 461. El autor advierte, para el derecho argentino, el riesgo latente de terminar reduciendo las garantías involucradas a la mera constatación de la existencia de fórmulas verbales burocráticas.

${ }^{68}$ Véase AlONSO (1999), pp. 242-243. El autor repasa una serie de fallos del Tribunal Supremo español en los cuales, en diversos grados o medidas, se cuestiona la validez o autenticidad del consentimiento de quien autoriza un autoriza la entrada y registro domiciliaria, cuando éste se encuentra detenido. En el mismo sentido, véase RIvEs (2004), pp. 67-70. El autor último citado, alude a una serie de fallos del Tribunal Supremo español, los que establecen que, por regla general, el consentimiento para el registro de una morada no puede ser concedido por un sujeto detenido, por cuanto se otorga en condiciones anímicas a las que se refieren globalmente como "intimidación ambiental". Por otro lado, se hace referencia a una línea jurisprudencial que ha desarrollado la vinculación de la renuncia con el derecho de defensa, en cuanto corresponde que el sujeto perseguido sea asesorado por un letrado, en todo acto en relación al cual pueda haber autoincriminación. Desde esa base, se postula en los fallos
} 
sus libertades ambulatoria y de comunicaciones, siendo probablemente más difícil que comprenda que no está obligado a tolerar una intromisión a su vivienda, cuando en realidad se encuentra forzado a soportar una injerencia más violenta en sus derechos fundamentales, como es su la privación de libertad ${ }^{69}$. La intervención o requerimiento del personal policial, ya puede introducir una dosis coercitiva que impresione a un ciudadano normal como sin mayores opciones de repeler un requerimiento de los agentes. Al respecto, Maier ha declarado que "... en efecto, la sola presencia de la fuerza pública implica, en la vida real, coacción suficiente para producir un consentimiento viciado $\mathrm{o}$, al menos, otorgado con error acerca de la facultad del requirente, y, por lo demás, a la misma fuerza pública le es posible emplear mecanismos sutiles de coacción, que no se reflejarán al juzgar el acto, o fáciles de ocultar al documentarlo o para el caso de intentar su reconstrucción judicial" (Maier, 1989, p. 457 $)^{70}$.

citados por el autor que, en relación con el sujeto detenido, sólo puede allanarse su morada cuando la autorización del sujeto se otorgue con la asistencia de un letrado.

${ }^{69}$ Véase BAytelman (2002), pp. 267-268. A propósito del derecho a guardar silencio y el desarrollo jurisprudencial de dicha prerrogativa en Estados Unidos de América, los interrogatorios policiales (para nuestros efectos, entendemos que no existe diferencias con la petición de un consentimiento) son diligencias inherentemente coercitivas, en donde se expone al sujeto a una atmósfera desconocida, rodeado de agentes antagonistas, aislado de apoyos externos, sometido a una constante persuasión la que incluso es enseñada en los propios manuales policiales.

70 Véase FIORentino, Diego E. - CSJN - 27/11/1984. La Corte Suprema argentina, en un fallo que se considera icónico en el sistema transandino, aquel tribunal, luego de descartar que en el caso concreto existiese en realidad consentimiento, expone que aun cuando así hubiese sido "... el permiso que podría haber otorgado [el sujeto detenido] carecería de efectos por las circunstancias en que se prestó, al haber sido Fiorentino aprehendido e interrogado sorpresivamente por una comisión de 4 hombres en momentos en que ingresaba con su novia en el hall del edificio donde habitaba, quedando detenido... a lo que se suma la inexperiencia del imputado en trances de ese tipo, factor que puede presumirse en razón de su edad y de la falta de antecedentes judiciales". Subyace en estas afirmaciones que el consentimiento otorgado por un sujeto detenido, en un contexto evidentemente coercitivo y amenazante, no es fiable, por lo que no es posible comprender que existió una renuncia de índole voluntario a la garantía de la inviolabilidad del hogar. Véase, también, en similar sentido: Corte Suprema, rol № 63052010, de 19 de octubre de 2010. La Corte Suprema, a propósito de la interrogación de un menor imputado, declara que "... no debe obviarse que el acusado fue conducido a la unidad para un control de identidad, por haber sido mencionado como uno de los autores de un ilícito gravísimo, por lo que su voluntad y estado emocional, habida cuenta de tratarse de un menor de 15 años, necesariamente debieron estar alterados, lo que es normal, razonable y esperable no sólo en personas adolescentes sino también en sujetos adultos, al verse enfrentados a una imputación de esta naturaleza...". Este último, estimamos, se trata de un criterio aplicable a la autorización de registro de lugares cerrados, toda vez esta última y la interrogación comparten en común una naturaleza evidentemente autoincriminatoria. Por otro lado, la detención, desde el punto de vista de la coerción, es incluso legalmente más severa que el control de identidad, siendo un procedimiento más intimidatorio, desde que, por ejemplo, el justiciado puede ser encerrado en celdas. 
La omisión del legislador procesal penal en la especificación de requisitos de fondo de la autorización, estimamos, no puede leerse como la inexistencia de los mismos. En las dos normas precitadas al comienzo de este apartado, sólo es posible constatar una explícita exigencia en torno al consentimiento: tratándose de la autorización voluntaria del afectado, para el registro de un recinto cerrado, ésta deberá ser expresa. Sin embargo, consideramos que no es posible el análisis judicial sin detenerse en la calidad del consentimiento, esto es, la existencia de un real conocimiento del sujeto en torno a su situación procesal y de la auténtica posibilidad que tiene de no acceder a la medida. Para que el consentimiento pueda estimarse válido, debe ser otorgado por la persona afectada comprendiendo el contexto judicial en que se desarrolla la petición de voluntariedad y sí y solo sí ha mediado por parte de los agentes, la explicación detallada y entendible, que tiene la posibilidad real de rechazar la medida, sin que se le advierta de consecuencias jurídicas nefastas de ningún tipo. La voluntariedad a que nos referimos implica también comprender que, en caso de no acceder a la medida de forma voluntaria, y que el persecutor decida insistir en ella, deberá solicitarse la intervención de un juez de garantía, órgano imparcial, que deberá ponderar el fundamento y la necesidad de la medida ${ }^{71}$.

Tratándose de la declaración del imputado, el ordenamiento procesal ha exigido que por regla general la renuncia al derecho a guardar silencio se haga contando con un defensor, o en su defecto, ante la presencia del fiscal, o bajo su responsabilidad (artículo 91 del CPP). A su turno, por su sola calidad de imputado, deberá ser informado de manera específica y clara de los hechos que se le imputan y que en caso de renunciar a su derecho a guardar silencio ello no podrá acarrearle ninguna consecuencia adversa (artículo 93 letras a y g del CPP). En el mismo sentido, se exige por el legislador que "si el imputado se allanare a prestar declaración... antes de comenzar el fiscal le comunicará detalladamente cuál es el hecho que se le atribuyere, con todas las circunstancias de tiempo, lugar y modo de comisión, en la medida conocida, incluyendo aquellas que fueren de importancia para su calificación jurídica, las disposiciones legales

\footnotetext{
71 Véase Dressler y Michaels (2013), pp. 249-250. El autor, siguiendo la doctrina de la Corte Suprema de Estados Unidos de América, expresa que la voluntariedad que genera un consentimiento efectivo, debe ser determinada sobre la base de todas las circunstancias concurrentes en el caso individual que se juzga. Entre los factores sospechosos de una autorización viciada o forzada, se encuentran: (1) la exhibición de fuerza o de armas por la policía, lo que sugiere que la persona no tiene la alternativa de rechazar el ingreso; (2) la presencia de un relevante número de agentes policiales que sugiera la idea que la policía va a proceder aun sin la cooperación del ciudadano requerido; (3) reiteración en el requerimiento de consentimiento pese a la negativa inicial del ciudadano; (4) cuando teniendo en vista la edad, sexo, raza, nivel educacional, estado emocional o condición mental de la persona que consiente, puede desprenderse que su permiso no es sino el resultado de una presión creada como consecuencia de la conducta de los agentes.
} 
que resultaren aplicables y los antecedentes que la investigación arrojare en su contra" (artículo 194 del CPP). Como se aprecia, tratándose de la renuncia a una garantía procesal como lo es el derecho a guardar silencio, el legislador adopta múltiples medidas tendientes a asegurarse la calidad del consentimiento, arbitrios que van desde asegurarse la presencia por regla general de un letrado, que asegure el otorgamiento de información de mejor calidad, pasando por el señalamiento de los antecedentes que obran en contra del imputado que justifican direccionar la investigación en su contra, hasta la existencia de fórmulas sacramentales, como la del artículo 93 letra g) del CPP, exigencia que persigue la entrega de una advertencia informativa íntegra y cabal, que no pueda ser cercenada por la discrecionalidad o criterio del funcionario. No parece razonable colegir que tratándose de otras garantías fundamentales, consagradas incluso de manera expresa por el ordenamiento constitucional y de acciones también susceptibles de vincular al sujeto a un delito, el legislador ha renunciado a cualquier control de calidad sobre la voluntariedad. Siguiendo a Rives, para que exista consentimiento, en aquella parte que por ahora nos interesa, éste debe ser prestado "... consciente y libremente. Lo cual requiere... que no esté invalidado por error, violencia o intimidación de cualquier clase [y] que no se condicione, a circunstancia alguna periférica, como promesas...". (Rives, 2004, pp. 65-66) 72

La renuncia a la garantía de inviolabilidad del hogar, así como también a cualquier otra prerrogativa susceptible de ser cedida, coherente con la relevancia del derecho del que el individuo se desprende, sólo podrá ser concedida en condiciones que aseguren la adecuada comprensión de la relevancia procesal que puede tener la diligencia, su naturaleza, la posibilidad de negarse a la misma y la exclusión de cualquier tipo de presión o violencia para lograr la aquiescencia del afectado. Así también, y conforme se ha venido desarrollando, si bien no puede establecerse ex ante que el consentimiento otorgado por un sujeto detenido no sea válido, éste resulta al menos en principio sospechoso, por las condiciones en que éste se concede, debiendo por ello hacerse un examen de la voluntariedad que considere todos los factores de presión psicológica y anímicos a los que puede haber estado sometido el sujeto detenido.

\footnotetext{
72 Véase RivEs (2004), pp. 65-66. El autor sostiene un catálogo más extenso de requisitos que debe contener el consentimiento, alguno de los cuales serán abordados en este trabajo y otros que lo exceden. Así también, uno propio del ordenamiento positivo español, que por ello no se incluye en la numeración. Así, el autor sostiene que el consentimiento para ser válido debe ser: a) otorgado por persona capaz; b) otorgado de forma consciente y libre; c) estar registrado en una constancia documental, ya sea que se haya dado de forma escrita u oral; d) debe ser otorgado de manera expresa; e) debe ser concedida la autorización por el titular del domicilio, lo que no atiende a aspectos relativos al dominio, y f) debe ser otorgado para un asunto concreto.
} 
Como evidente corolario de lo anterior, si quien invoca la renuncia a una garantía básica, en principio libre de cualquier injerencia estatal, no puede probar que ella se realizó en condiciones de libertad e información de un nivel tal que justifique un consentimiento válido, la prueba obtenida como consecuencia del allanamiento de recinto cerrado, deberá ser excluida de consideración en el juicio oral.

\subsection{Algunos aspectos problemáticos exclusivamente relativos a la entrada y registro en lugares cerrados}

\subsubsection{Coexistencia de varias esferas de privacidad en un mismo domicilio}

El ingreso de agentes investigativos a una morada puede comprometer, dentro de otros derechos esenciales, la inviolabilidad del hogar, la privacidad y la propiedad, tanto del o los imputados, así como de terceros que no tienen relación alguna con el proceso en ciernes. En este contexto relativo a los potenciales afectados con las medidas intrusivas, abordaremos ya no al problema de la voluntariedad de la persona que concede la autorización, sino en la posibilidad jurídica que tuvo este sujeto para disponer del derecho amagado.

El artículo 206 del CPP faculta el acceso de los agentes estatales a un recinto cerrado en aquellos casos en que el "propietario o encargado" del recinto concede la autorización para ello. El asunto es de suyo sencillo cuando la propia persona afectada en sus derechos es quien renuncia voluntariamente a la protección jurídica sobre los mismos. Sin embargo, se torna una materia compleja y de fronteras imprecisas, cuando quien otorga la licencia no es la persona afectada con la medida ni comparte espacios o esferas de intimidad con el sujeto realmente afectado, o cuando su autorización no sólo compromete sus propias garantías esenciales, sino también las de un tercero.

En todo inmueble habitacional pueden convivir diversas personas, las que incluso podrían no tener mayor relación cotidiana entre sí. Es perfectamente posible concebir -y así sucede en la práctica policial- que un pariente de la persona investigada se encuentre encargado del recinto y autorice el ingreso policial. También puede suceder que la persona encargada del recinto sea alguien mandatado puntual y transitoriamente para cuidarlo, y no tenga mayor poder sobre las decisiones domésticas (cuidadores, jardineros, personal doméstico, gasfíter en labores, etc.). Puede también presentarse la situación, tratándose de hoteles, pensiones y recintos que reciben esporádicamente a pasajeros, que la persona encargada del mismo, en realidad, no tenga ningún grado de relación con la intimidad o privacidad de las personas que de paso allí se encuentran.

La ley no entrega mayores orientaciones para solucionar los problemas que la práctica de diligencias investigativas pueden acarrear. No tiene mayor sentido que el legislador haya solicitado la renuncia a una garantía a quien en realidad 
nunca la poseyó y que considere eso como antecedente suficiente para justificar una irrupción. La aceptación o renuncia voluntaria sólo puede recaer sobre un derecho que se posee o respecto de una garantía que se goza. Por ello, el sujeto que accede al allanamiento sólo puede renunciar a la inviolabilidad del hogar, en la medida que éste efectivamente sea el suyo o tenga sobre el mismo una expectativa razonable de privacidad, o haya sido designado como responsable del lugar con facultades para tomar decisiones relevantes en relación a éste ${ }^{73}$. Como consecuencia de lo anterior, si dentro del hogar existen habitaciones cerradas, muebles, o espacios que denotan de manera palmaria la utilización exclusiva y excluyente de los mismos por un sujeto diverso al que concede la autorización, no es posible para la policía o el Ministerio Público proceder sin recabar la correspondiente autorización judicial ${ }^{74}$. Así sucedería, verbigracia, si dentro del inmueble que se allana, una persona diversa a la que concede la autorización de registro, mantiene una dependencia cerrada con llave, se trate o no de una construcción independiente ${ }^{75}$.

\footnotetext{
${ }^{73}$ Véase Corte Suprema, rol № 7193-10, de 6 de diciembre de 2010. El Máximo Tribunal declara que no existe una legítima expectativa de intimidad que proteger, cuando el propio espacio que se reclama vulnerado por terceros, ha sido abierto precisamente a ellos mismos por parte del titular.
}

74 Véase Corte Suprema, rol № 25003-14, de 11 de diciembre de 2014. En dicha sentencia, la Excma. Corte, a propósito de una autorización dada por la propietaria del inmueble, que correspondía además a la madre del imputado, determina que "el ingreso al domicilio del acusado lo ha sido al margen de la ley", toda vez que "... aparece que el referido lugar no sólo alberga el domicilio de la señora XX [apellidos borrados por los autores], sino también el de al menos 3 personas más, que moran en sendas dependencias situadas aparte de las de ella, tan separadas e independientes que ellas se encontraban cerradas y sus seguros debieron ser abiertos con llaves por la autorizante".

75 Véase Dressler y Michaels (2013), pp. 255-259. Los autores explican que la jurisprudencia norteamericana ha desarrollado la doctrina del "third-party consent", construcción mediante la cual se intenta justificar la utilización de evidencia obtenida en registros autorizados voluntariamente, pero por un sujeto diverso a aquel en contra de quien se usa la prueba. En ese contexto se sostiene que personas que habitan un mismo inmueble, tienen el derecho recíproco de autorizar los allanamientos de áreas comunes. La cohabitación con otros sujetos implica asumir el riesgo social que se ventile la privacidad en aquellos espacios. Nótese que este criterio, en la línea con lo que acá se ha sostenido, implica que sólo podrá autorizar el allanamiento un sujeto residente en el lugar, titular también de la inviolabilidad del hogar que se pretende conculcar. En similar sentido, véase Rives (2004), pp. 62-65. El autor repasa relevante jurisprudencia del Tribunal Supremo español, fallos que, en consonancia con la tesis norteamericana, sostienen que cada uno de aquellos sujetos que comparten domicilio, se encuentran autorizados para disponer del derecho a la inviolabilidad del hogar, ello sobre la base que la cohabitación implica aceptar ciertas modulaciones basadas en la confianza recíproca que se asume que existe entre quienes cohabitan. La confluencia de varios derechos en un mismo espacio implica, sostiene la jurisprudencia citada, aceptar que el otro, en definitiva, pueda también disponer de ese espacio. Esta regla conocería una excepción, a saber, que no sería legítima la disposición cuando el tercero que autoriza, se encuentra en contraposición de intereses con el sujeto perseguido. Así, por ejemplo, tratándose de un matrimonio que habita en un mismo inmueble, un cónyuge víctima de un 
Conforme lo expuesto, tratándose de hoteles o residenciales, estiman estos autores, por los mismos fundamentos, que no es posible proceder sin la autorización de el o los pasajeros implicados en la medida o con la venia judicial, siendo insuficiente la manifestación de voluntad favorable del responsable o administrador del recinto de hospedaje. Aunque se trate de habitaciones pagadas y sólo usadas de forma transitoria, constituyen por ese período un verdadero domicilio de quienes allí habiten, siendo lugares en los que los sujetos desarrollan su vida doméstica, existiendo además una legítima expectativa de privacidad que proteger. Así, se ha manifestado que "... ni la accidentalidad, temporalidad, o ausencia de habitualidad del uso de la habitación del hotel, ni las limitaciones al disfrute de las mismas que derivan del contrato de hospedaje, pueden constituir obstáculos a su consideración como domicilio de los clientes del hotel mientras han contratado con éste su alojamiento en ellas. Siendo las habitaciones de los hoteles espacios aptos para el desarrollo o desenvolvimiento de la vida privada, siempre que en ellos se desarrolle, constituyen ámbitos sobre los que se proyecta la tutela...". (Rives, 2002).

No es posible pasar por alto que muchas veces determinar las características de un lugar, las facultades del encargado, o la existencia de diversas esferas de derechos, será de considerable dificultad, tratándose además de un asunto fundamentalmente fáctico y variable. Por ello, deberán las interrogantes que emerjan ser resueltas teniendo a la vista las particulares circunstancias del caso que se analice ${ }^{76}$. El fiscal investigador y la policía están facultados para adoptar constantemente decisiones durante el proceso de recolección probatoria, mismas que serán objeto de eventuales cuestionamientos por la defensa y de revisión por parte de la instancia judicial. Por ello, la renuncia del sujeto habilitado a prescindir de la protección de su derecho, debe ser razonablemente explicada a nivel intersubjetivo, comenzando por la legitimidad que tiene el mismo para disponer de aquél77. Siendo así, el examen no puede agotarse en

delito, no podría autorizar la entrada y registro al propio lugar en que reside, cuando lo que se recaba en realidad es prueba inculpatoria respecto su consorte imputado.

${ }^{76}$ Véase CARRIÓ (1994), p. 268. El autor propone el criterio de la "razonable expectativa de intimidad", como instrumento para resolver casos limítrofes o críticos, en relación a esta garantía esencial. Aplicando este criterio, en lo que nos interesa, podremos determinar el carácter de privado de un recinto y la titularidad del sujeto afectado con la renuncia. Para ello, será necesario indagar si la persona ha manifestado de alguna forma tener una expectativa o interés de mantener un determinado espacio para un uso personal, con exclusión de la inferencia de terceros. Sostiene que, si se trata de una reserva razonable, el Estado está obligado a respetarla y tolerarla.

77 Véase Corte Suprema, rol № 25003-14, de 11 de diciembre de 2014. Con acierto, la Excma. Corte observa que la regla de autorización "... ha de ser interpretada en relación a la garantía constitucional que tutela la privacidad del afectado y no la propiedad, situación entonces que demanda un mínimo 
la constatación de una seña sacramental o de una manifestación estereotipada, carente generalmente de todo contenido, dando por supuesto que un sujeto puede, mediante un acto personal, y por el solo hecho de encontrarse en una determinada posición, comprometer derechos esenciales de terceros ${ }^{78}$.

A las conclusiones expuestas fuerzan el claro tenor del artículo $19 \mathrm{~N}^{\circ} \mathrm{s} .4^{\circ}$ y $5^{\circ}$ de la CPR, preceptos que mandatan que por regla general las personas gozan del derecho a la privacidad y la inviolabilidad del hogar, siendo, por ende, las limitaciones a los mismos de naturaleza excepcional. Por otro lado, el propio CPP en su artículo $9^{\circ}$ dispone que la regla general en materia investigativa es que las diligencias perturbadoras de garantías deben ser autorizadas judicialmente. Finalmente, en el mismo sentido, el artículo $5^{\circ}$ del mismo cuerpo legal expresa que si es el imputado el afectado con la medida intrusiva o la restricción de un derecho, estas limitaciones deben ser interpretadas de forma restrictiva.

La breve revisión descrita, da cuenta que esta concepción restrictiva de la capacidad para renunciar a las garantías resulta de una estructura normativa donde la injerencia del Estado -o la justicia del Estado- en los derechos fundamentales ha sido concebida como un arbitrio de carácter excepcional. No debe perderse de vista que la regla general es la vigencia de la garantía, y las intromisiones estatales son de carácter excepcional. Por ello, si las características del lugar, o la información que se dispone por parte de los agentes, no permiten con claridad determinar la naturaleza del lugar o la capacidad del sujeto para renunciar a la garantía, la fuerza policial deberá abstenerse de actuar y sólo será procedente un ingreso mediando autorización judicial.

La importancia de este tema resulta cardinal. El ingreso policial a un recinto sin contar con la autorización de una persona válidamente facultada para ello (ni con orden judicial) acarreará que la prueba deba ser considerada obtenida con infracción a las garantías fundamentales comprometidas y, ergo, que deba ser excluida del juicio.

\subsection{Existencia de varios domicilios en un mismo predio}

El objeto de análisis en esta categoría de hipótesis, radica en los casos de autorizaciones judiciales concedidas para realizar allanamientos en un inmueble

de actividad por parte de las policías, en orden a establecer acertadamente la identidad del titular del derecho que va a ser lesionado".

${ }^{78}$ Los errores en el proceder investigativo policial que hayan sido generados actuando el agente en la creencia de obrar respetando las garantías fundamentales, podrán ser enmarcados dentro de las excepciones a la exclusión probatoria de la prueba ilícita, amparándose, en la medida que se cumplan sus presupuestos, en la llamada doctrina de la buena fe del transgresor. Véase HerNández (2005), pp. 73-75 y ARMENTA (2009), p. 123. 
determinado, lugar en donde, sin embargo, existen diversos hogares, diferenciables desde un punto de vista físico y de organización familiar. Generalmente es posible apreciar este tipo inmuebles en zonas semirurales o de escasa urbanización. En éstos, incluso, bajo una misma numeración y calle, es posible divisar una propiedad, en apariencia única, que sin embargo sólo es la fachada de un sitio que contiene distintas residencias privadas.

Dejando de lado las peculiares características de estos recintos y las implicancias que ello podrían tener en materia de error, se trata de casos en que existe un solo recinto inmueble, pero contenedor de varios domicilios, funcional y físicamente diferenciables. Se trata, como se aprecia, de varias esferas de privacidad e inviolabilidad del hogar que coexisten en un mismo espacio físico territorial.

A nuestro juicio, la autorización judicial concedida para el ingreso a una propiedad ubicada en una calle específica y bajo una numeración determinada no habilita la revisión de todos los hogares que se puedan encontrar emplazados en el mismo sitio. Las autorizaciones judiciales son concedidas sobre la base de una sospecha determinada y concreta respecto a la comisión de un delito, por una persona específica, ya sea que esté completamente individualizada o no. La correcta ponderación de la autorización judicial debió exigir justificar razonablemente la conexión entre el hecho que se investiga y el mentado inmueble, así como la necesidad investigativa que se vería satisfecha al allanar el lugar. Todo ese proceso se realiza sobre un recinto concreto, en donde reside o habita el o los sujetos sospechosos. La mera casualidad que el predio contenga otros inmuebles habitados por distintos grupos familiares, no justifica un allanamiento que vulnere otras esferas de intimidad que superen el objetivo inicial ${ }^{79}$.

\footnotetext{
${ }^{79}$ Véase en sentido contrario Corte Suprema, rol № 11403-2011, de 16 de enero de 2012. El Máximo Tribunal, si bien pone en duda que existan dos domicilios en un mismo inmueble, esto debido a que las mismas son unas "construcciones precarias, las que difícilmente pueden ser calificadas como constitutivas de una residencia autónoma", ello se trata de un hecho no resuelto, toda vez que la precariedad o fragilidad de la obra no constituye un elemento idóneo para descartar la existencia de una morada, siendo lo determinante la existencia o no de una legítima expectativa de intimidad, situación no abordada. No obstante ello, dicho tribunal manifiesta que tampoco resulta posible exigir a los policías su abstención, cuando "la orden en virtud de la cual se ingresó al domicilio referido fue obtenida legalmente respecto del único inmueble cuya identidad se ha acreditado en el juicio, el único observable desde el exterior y que se conocía hasta ese momento, no siendo posible exigir a los funcionarios policiales la capacidad de intuir que existía otra residencia separada en el patio". Dicho criterio no es compartido por estos autores, desde que si la orden fue concedida respecto de un domicilio determinado, que contiene una numeración precisa y resulta observable desde la vía pública, no se entiende el porqué, una vez descubierta la existencia de dependencias posibles de constituir un domicilio diverso, se extiende el registro a éstas, a pesar de que ello no fue objeto de la petición judicial, ya que ni siquiera, como se señala, ello era intuido por los agentes. En sentido contrario, a propósito de una entrada y registro a un inmueble con autorización viciada de una tercera persona,
} 
Naturalmente, esto sin perjuicio que la autoridad judicial pueda extender la autorización de la medida intrusiva a otras residencias, dentro del mismo predio, mediante una nueva resolución.

Tal como se afirmara supra (5.2.) podrá defenderse la inclusión de las pruebas obtenidas en un allanamiento que se hizo extensivo a otros inmuebles habitados por otros grupos familiares, cuando las condiciones físicas del lugar, de manera razonable, no permitieron al agente policial, actuando de manera diligente y de buena fe, comprender que en realidad estaba extendiendo su registro a un domicilio diverso de aquel que era el objetivo de su investigación. Con todo, resultará esencial la fundamentación que se pretenda usar para explicar el instituto de la prueba ilícita, toda vez que si la misma no sólo busca disciplinar agentes policiales, sino también asegurar el imperio de los derechos esenciales, la sola buena fe del agente no hace desaparecer la necesidad de suprimir la prueba (véase el apartado 4.6.).

\subsection{Aspectos problemáticos en relación al control de identidad}

A continuación abordaremos lo que consideramos uno de los tópicos más fructíferos en materia de declaraciones de ilicitud probatoria, así como también quizá uno de los más recurridos a la hora de justificar decisiones judiciales absolutorias y declarar ilegalidades de detenciones. La razón parece ser el resultado de una ecuación que reúne a variados factores críticos. En primer término, el control de identidad se trata de un procedimiento idóneo para afectar o amenazar garantías esenciales de los ciudadanos, tales como la libertad ambulatoria, la privacidad e indirectamente la propiedad, con ocasión de las incautaciones que pueda dar lugar el procedimiento ${ }^{80}$. En segundo lugar, justifica la fructificación de la vigencia de este problema, el hecho que se trata de un procedimiento que la policía, conforme lo dispone el artículo 85 del CPP, puede realizar de forma autónoma, es decir, "sin orden previa de los fiscales" y sin que exista tampoco una obligación manifiesta de reportar o registrar sus resultados. Así, la policía puede ejecutarlo sin recabar una autorización de un tercero imparcial como lo es el juez de garantía y sin contar tampoco con las directrices o apoyo de un especialista en temas jurídico-investigativos, como lo

véase Corte Suprema, rol № 25003-14, de 11 de diciembre de 2014. En dicho fallo, el referido tribunal se muestra menos tolerante con el actuar policial exigiéndole proactividad en la determinación de elementos fácticos del inmueble, siendo necesario "... un mínimo de actividad por parte de las policías, en orden a establecer acertadamente la identidad del titular del derecho que va a ser lesionado".

${ }^{80}$ Véase Corte Suprema, rol № 2346-2013, de 3 de junio de 2013. El fallo destaca de manera superlativa la afectación de la intimidad corporal, pudor y dignidad humana, que un procedimiento de registro corporal, en el contexto de un control de detención, puede llegar a afectar. 
es el fiscal. Finalmente, completa el espectro que le otorga contingencia al tema, el hecho que el instrumento legal del citado precepto se construye sobre la base de facultades cuyos fundamentos han sido sólo esbozados por el legislador y delineados de manera gruesa, entregando a la jurisprudencia y la dogmática la elaboración de contornos más precisos.

Los aludidos factores provocan que el control de identidad se convierta en un tema objeto de relevantes debates, donde confluyen, por un lado, las necesarias facultades preventivas de la policía, necesarias siempre para anticiparse al delito y no sólo reprimirlo y, por otro, porque la indefinición que le es inherente al instituto y los derechos en juego, constituyen un fértil terreno donde es posible que proliferen abusos en el proceder policial.

Dicho lo anterior, nos abocaremos en las líneas siguientes a tratar algunos tópicos que consideramos relevantes y a la vez conflictivos en relación a este tema, sin pretender, advertimos desde ya, agotar un tópico que se presenta mucho más extenso.

\subsubsection{Existencia de "indicios" que habilitan para la realización del procedimiento (pluralidad o singularidad de los elementos y gravedad)}

El primero de los asuntos controvertidos, que surge de la propia literalidad del texto del artículo 85 del CPP, es la interrogante acerca de si sólo habilita para la realización del control de identidad una pluralidad de "indicios", o sí basta para ello la existencia de un elemento único. Para algunos autores nacionales, por razones más bien históricas, relativas a la modificación que sufrió en el año 2008 el precepto referido, mediante la dictación de la ley № 20.253, la actual redacción de la norma evidenciaría que la voluntad legislativa es la de requerir para proceder al control de identidad la existencia de una pluralidad de antecedentes, ya que se modificó la fórmula singular previamente usada ("indicio") sustituyéndola por la actual ${ }^{81}$. Por ello, un único elemento de sospecha no sería suficiente para justificar el someter a una persona al mentado procedimiento.

Estimamos que una correcta lectura del texto precitado, más la comprensión sistemática de la norma, conducen a desechar esta propuesta interpretativa. En primer término, el artículo 85 inciso $1^{\circ}$ del CPP utiliza una fórmula de redacción general, que intenta reglar estos procedimientos haciendo referencia a las distintas hipótesis que pueden presentarse en cada uno de ellos. Así, queda evidencia en las menciones "Ios funcionarios policiales", a los "casos fundados", el suministro de "informaciones", los "documentos de identificación", así como también la vinculación que pueda hacerse con "un crimen, simple

81 En este sentido, véase Otero (2008), p. 63 y SALAS (2012). 
delito o falta", referencias todas alusivas a una amplia categoría de supuestos, en consonancia con la referencia a los indicios habilitantes.

Por otro lado, una interpretación como la propuesta resulta inarmónica con todo el resto del sistema procesal penal que instaura nuestro CPP. Una exigencia meramente numérica y formal, resulta un injerto ajeno a toda la estructura valorativa de pruebas y antecedentes que se estructura a lo largo del articulado del citado cuerpo legal. Nótese que ni la forma de probar en juicio (artículo 295 del CPP) ni el estándar de convicción para condenar a un sujeto (artículo 340 del CPP), así como tampoco los requisitos relativos a la prisión preventiva, o la detención (artículos 140 y 130 del CPP, respectivamente), que son medidas tremendamente más severas y agresivas contra los derechos esenciales que el control de identidad, han exigido requisitos numéricos de ningún tipo, lo que resultaría, por lo demás, disonante absolutamente con un sistema basado en la libertad probatoria. En un ordenamiento procesal en donde las pruebas y los antecedentes de convicción son pesados y calibrados, las consideraciones meramente aritméticas no tienen lugar. Un solo antecedente puede resultar mucho más sugerente y poderoso que la existencia de varios de ellos, así, también, un procedimiento fundado en varios indicios, de los que alude el artículo 85 del CPP, puede resultar más infundado que aquel cimentado en la presencia de un elemento aislado. Sencillamente, no puede encontrarse en este pretendido elemento interpretativo un coto de racionalidad a los procedimientos de control de identidad.

El asunto que genera mayores diferencias jurisprudenciales y complejidades a la hora de analizar el instituto, lo es sin duda la exigencia legal que el antecedente que justifica el procedimiento se encuentre dentro de lo que el artículo 85 del CPP ha denominado "casos fundados", lo que serían aquellos "... en que, según las circunstancias (se pueda estimar) que existen indicios de que ella hubiere cometido o intentado cometer un crimen, simple delito o falta; de que se dispusiere a cometerlo; de que pudiere suministrar informaciones útiles para la indagación de un crimen, simple delito o falta".

Se podrá adivinar que esforzarse por determinar las fronteras de este instituto se trata de un ejercicio de la mayor relevancia, toda vez que siendo el control de identidad susceptible de amagar derechos esenciales como son la libertad ambulatoria, la intimidad y la propiedad, un ejercicio de este mecanismo, fuera de las hipótesis autorizadas por el legislador, debería conducir a la declaración de ilicitud probatoria, ya sea en la audiencia de preparación del juicio oral, por el juez de garantía o, por la propia Excma. Corte Suprema, conociendo del recurso de nulidad.

En opinión de estos autores, la exigencia de racionalidad del procedimiento de control de identidad viene dada por la existencia de "indicios" que demanda 
la norma, los que deben ser dotados de contenidos y completados por la jurisprudencia. Será la existencia de indicios lo que dote de sensatez a las deducciones policiales que se extraigan a partir de ellos, las que en conjunto construyan el "caso fundado" a que se refiere el artículo 85 del CPP82.

Las referencias de la doctrina a los requisitos de fondo del procedimiento de control de identidad son más bien escasas. Para Otero la existencia de indicios “... implica que deben existir hechos reales, claros y precisos -no deducciones u olfato policial-que racionalmente permitan estimar que existe el supuesto legal que permite realizar el control de identidad" (Otero, 2008, p. 63) ${ }^{83}$. Para Rabi, el indicio constituiría un elemento fáctico conocido, mediante el cual, el agente policial, considerando todas las circunstancias que aprecia, colige que el sujeto afectado con la medida podría tener alguna de las vinculaciones detaIladas en la ley, con un hecho que, en términos genéricos, reviste caracteres de delito, apareciendo además la medida como necesaria para desarrollar algún curso policial de carácter preventivo o investigativo ${ }^{84}$.

En nuestra opinión, la existencia de "indicios", como se lee del artículo 85 del CPP, son siempre elementos fácticos concretos, sobre la base de los cuales pueden determinarse algunas de deducciones que prevé el legislador: que un sujeto delinquió o intentó delinquir, que se prepara para cometer un delito, o que dispone de información relevante para aclararlo ${ }^{85}$.

Los indicios consisten, en nuestra opinión, en elementos de hecho que permiten colegir que el sujeto controlado se encuentra vinculado a un suceso delictivo (sea falta, simple delito o crimen), ya sea que aparezca razonable suponer que tiene responsabilidad penal en éste o que mantiene en su poder algún elemento informativo relevante, en relación al mismo. Para poder determinar cuál es la

\footnotetext{
${ }^{82}$ Véase RABI (2010), pp. 342-343. El autor sostiene que junto con la existencia de indicios, la racionalidad del procedimiento también debe ser controlada en relación al elemento "casos fundados" a que alude el artículo 85 del CPP. Esta exigencia sería un llamado a controlar la idoneidad del procedimiento de control en relación a los fines policiales perseguidos, o dicho de otra forma, corresponde revisar si el mecanismo de control empleado contribuía realmente para el objetivo investigativo al que estaba orientado. En opinión de estos autores, ese control no es posible de realizar o no al menos de la forma propuesta. Los tribunales no tienen mayormente funciones relativas a la selección de las medidas investigativas, ni la eficiencia de los procedimientos o pesquisas, ni menos aún tienen injerencia respecto a los mecanismos policiales preventivos. Sin embargo, es indudable que la idoneidad del control o su intensidad -asumiendo que no todos afectan las mismas garantías ni lo hacen en la misma medida- puede ser revisada vía principio de proporcionalidad, cuando la necesidad investigativa que la justifica aparece como ínfima o irrelevante en torno al procedimiento utilizado.

${ }^{83}$ El destacado es del propio autor citado.

${ }^{84}$ RABI (2010), pp. 349-353.

${ }^{85}$ El artículo 85 del CPP expresamente hace aplicable el instituto en estudio, tratándose el delito presumido de un crimen, simple delito o falta.
} 
gravedad o seriedad que se requiere que tengan estos elementos fácticos, como punto de partida conviene señalar que este mecanismo, como emana del propio artículo 85 del CPP, no sólo está dirigido en contra de un sujeto imputado, sino también de quien se presenta como testigo. También conviene hacer presente que no sólo, conforme se lee, el indicio permite efectuar deducciones respecto de hechos pasados, sino también presumir sucesos futuros probables, lo que no es sino, aunque el término no guste, la construcción de una sospecha delictiva. Esta invitación a especular sobre los comportamientos futuros de un sujeto, por cierto, introduce un alto grado de indeterminación al instituto.

Empero, lo anteriormente descrito no puede ser un obstáculo que excuse avanzar hacia una definición del indicio. El CPP, como instrumento regulador del conflicto pretensión punitiva versus derechos esenciales, que convive en todo sistema penal, ha establecido una serie concatenada de formas regladas de afectación de derechos esenciales en el contexto de un proceso. Las vulneraciones más severas a los derechos esenciales tienen exigencias más altas, las que se van atenuando en la medida que la intromisión estatal se hace más leve.

Así, para condenar a un sujeto y poder privarlo de su libertad ambulatoria y la propiedad, en su caso, se requiere por exigencia del artículo 340 del citado cuerpo legal, certeza que supere la duda razonable. Esto quiere decir que la tesis que los jueces de fondo estiman que probatoriamente se impuso, no aparezca sólo como probable, sino como una alternativa que con certeza concurrió, más allá de cabos sueltos que puedan quedar en el proceso reconstructivo histórico. Para decretar la prisión preventiva, en cambio, por mandato del artículo 140 del mismo Código, se requieren antecedentes que justifiquen la existencia del delito, que permitan presumir la participación del sujeto y que resulten calificados e indispensables para satisfacer algún tipo de necesidad de cautela de las que dicha norma prevé. Como se aprecia, lo exigido acá ya no es un estándar de certeza, sino de factibilidad o probabilidad razonable, que la causa incoada en contra del imputado terminará en una condena en su contra. En un grado ya de afectación menor de las garantías esenciales se encuentra la detención, que si bien afecta la libertad ambulatoria de un sujeto, ésta tiene un carácter esencialmente temporal. El artículo 130 del CPP consagra las hipótesis de flagrancia, las que como ya adelanta la propia etimología de la voz usada, se trata de casos de evidencia palmaria en torno a que se está cometiendo o acaba de cometerse un delito. Así, cuando existen elementos fácticos que comunican que un delito está "en llamas" o "ardiendo", se autoriza que el ciudadano o el policía priven de libertad a un sujeto, de forma transitoria, la que en principio no puede exceder de 24 horas y para el único efecto de ponerlo a disposición de la autoridad judicial. En esta última hipótesis, si bien se exige la constatación de la evidencia de un delito, no se precisa construir ningún tipo 
de raciocinio sobre la fortaleza de la causa probable que en contra del sujeto podría seguirse, ni menos construir certezas, cuando en realidad de los hechos escasamente se sabe ${ }^{86}$.

Aunque el instituto del control de identidad no sólo tiene finalidades investigativas o procesal penales, sino también otros objetivos de índole preventivos, constituye uno de los mecanismos que establece también el legislador como arbitrio al servicio del descubrimiento de la "verdad". Dentro del catálogo descrito, es la intromisión más leve en los derechos esenciales, puesto que en su modalidad de ejecución más severa sólo puede implicar una privación de libertad que en ningún caso podrá superar las ocho horas de extensión. Como ya hemos referido, la realización de un control de identidad demanda la concurrencia de indicios. Nos parece correcto asumir que esta exigencia nos sitúa en un estadio lejano a cualquier certeza o presunción de causa probable en contra del sujeto controlado. Huelga también señalar que lógicamente un indicio que habilita para realizar una suposición (un delito) se trata de algo valorativamente inferior que la constatación de una flagrancia, hipótesis en la cual la deducción que en el caso se ha cometido un ilícito resulta obvia. Aunque como hemos dicho el control de identidad también puede afectar a testigos, normalmente se ejecutará sobre personas respecto de las cuales se sospecha su participación en algún suceso ilícito, ergo imputados. En relación con los indicios, no es posible exigir un grado de vinculación tan alto entre el sujeto controlado y un delito, que lo transforme en una deducción inmediata y directa. Interpretar con tal grado de exigencia la voz "indicios", tornaría en realidad al control de identidad en impracticable, toda vez que cuando existan antecedentes que de forma inequívoca permiten vincular a un sujeto (imputado) con un delito, en realidad la policía, más que efectuar el control, debería proceder a la detención por flagrancia. Una interpretación así, que condena al desuso de la norma, no puede ser adoptada.

El indicio, este elemento fáctico que vincula a un sujeto con un delito, por definición, nunca hará tal nexo de manera certera y precisa. La imprecisión es de la esencia y forma parte de la naturaleza de este instituto. Las vinculaciones evidentes u ostensibles en realidad, al menos tratándose de nexos relativos a imputados, son propias de institutos como la flagrancia, la prisión preventiva, o la condena. El control de identidad, herramienta de carácter fundamentalmente investigativo, parte del supuesto que gran parte del fenómeno delictivo no es

\footnotetext{
${ }^{86}$ Véase, Corte Suprema, rol No 181-2013, de 19 de febrero de 2013. La Excma. Corte Suprema, concordante con el criterio expuesto, declara que el control de identidad "... constituye una atenuada irrupción sobre la libertad personal, y por ello el estándar exigido por la norma es menor al de las medidas cautelares y, ciertamente, al de la sentencia".
} 
conocido por la autoridad y que sólo se está evidenciando un fragmento o retazo de éste. En los casos de control de identidad, como la exigencia es menor, las prerrogativas estatales también lo son, en coherencia con esta escala graduada de instrumentos procesales penales que contiene el CPP. Aunque el concepto resulte algo odioso y se encuentre bastante desprestigiado, no es sino el indicio la regulación procesal acerca de cómo canalizar una sospecha policial.

Resulta también evidente, que como la norma del artículo 85 del CPP comporta un grado de afectación a los derechos esenciales y que no se ha otorgado a la policía un instrumento ilimitado sino que reglado, la exigencia de "indicios", también, debe ser algo más que el puro arbitrio, capricho o prejuicio de los agentes. Situándose en un grado intermedio, entre la constatación palmaria que se está cometiendo un delito y el mero arbitrio, se ubica el indicio. Éste es el elemento que permitirá colegir, aunque aún con un grado de indeterminación más o menos relevante, que se puede vincular al sujeto controlado con algún ilícito ya ejecutado o en marcha. Dicho de otro modo, el comportamiento del sujeto controlado, las especies que porta, el contexto espacial en que se sitúa la conducta dudosa; una denuncia recibida de un transeúnte, o proporcionada de forma telefónica, el comportamiento nervioso de los sujetos, a modo de ejemplo, son factores que permitirán entregar al policía información que lo que tiene ante sí, no son ni más ni menos que elementos normalmente asociados a un delito ${ }^{87}$. La situación que el policía aprecia, es una fotografía que da cuenta de un elemento que permite sugerir que en realidad se está en presencia de una película o secuencia más compleja, que aunque desconoce en gran medida, puede razonablemente presagiarla. Al contrario, los antecedentes provenientes de fuentes escasamente creíbles o dudosas, así como aquellos que no permitieren

\footnotetext{
${ }^{87}$ Véase Corte Suprema, rol № 6393-2011, de 12 de octubre de 2011. La Excma. Corte declara que la revisión de los presupuestos del control de identidad, debe hacerse "... en relación a todo el contexto del hecho...". En dicho fallo, el Máximo Tribunal considera que el hecho de encontrarse la policía "... precisamente haciendo vigilancia preventiva de delitos relacionados al narcotráfico... en un sector del cual manejan antecedentes que se comercializa droga... [sumado a que los sujetos controlados]... se detuvieron por más de siete minutos en ese lugar y que ambos ocupantes del móvil se veían nerviosos y atentos a los espejos y ventanas del coche, como si esperasen a alguien..." son circunstancias que justifican el control de identidad que se impugnaba en el recurso. En el mismo sentido, véase Corte Suprema, rol № 15198-13, de 15 de enero de 2014. El mismo tribunal ya referido, insiste en la idea que "Ios indicios vienen dados por el contexto íntegro en que se produjo la detención [se refiere en realidad el razonamiento al procedimiento de control de identidad]...". Sostiene que si bien en determinado contexto el guardar especies puede ser un acto neutro, cuando esto se produce de noche, en medio de un "patrullaje preventivo en un sector en que conocidamente se comercializa mucha droga" y, ello, sumado a que el sujeto esconde algo "en la pretina del pantalón en lugar de hacerlo en el bolsillo, sólo cuando vio que se aproximaba Carabineros", son indicios suficientes para proceder al control de identidad.
} 
razonablemente realizar, por su neutralidad, una posible conexión con un hecho delictivo debiesen ser descartados como indicios suficientes ${ }^{88}$.

Es una empresa inagotable, y quizá inútil, establecer un catálogo de elementos, ya que los casos que pueden presentarse siempre manifiestan particularidades y un elemento que puede parecer razonable en un contexto, podría no serlo en otro. Un sujeto corriendo en velocidad en una costanera, con ropa deportiva, nos puede sugerir que éste se encuentra realizando algún tipo de actividad física recreacional. Sin embargo, un sujeto corriendo en una zona céntrica densamente poblada, puede para el policía ser motivo suficiente para controlar la identidad del sujeto, si momentos antes, un transeúnte, le ha alertado al agente, que en las inmediaciones del sector ha ocurrido un denominado "lanzazo". En el mismo sentido, portar un combo o un napoleón en una feria de aquéllas en que se venden productos usados, se tratará de un comportamiento neutro; mientras que hacerlo de madrugada, en una zona comercial desolada, podrá ser un indicio para un control.

Como sea, si el control de identidad ha devenido en algún tipo de recolección probatoria que pueda ser cuestionada en su ilicitud, el mecanismo para justificar el adecuado uso del procedimiento será la fundamentación policial contenida en el registro que dé cuenta de la diligencia, la que deberá permitir reproducir y ponderar los antecedentes tenidos a la vista por los agentes al momento de proceder el control. La vaguedad e imprecisión de los registros sobre este tópico, o la sola referencia a frases hechas y lugares comunes, en definitiva, complota contra la propia justificación del proceder policial, toda vez que no será posible revisar la racionalidad del mismo.

Toda revisión judicial que se haga sobre la validez o razonabilidad del control de identidad, debe fundarse en un análisis que sitúe ficticiamente al

\footnotetext{
${ }^{88}$ Véase Corte Suprema, rol № 2346-2013, de 3 de junio de 2013. Aun cuando la jurisprudencia de la Excma. Corte Suprema no ha sido uniforme sobre el tópico, en el caso se estima que el control de identidad que "no tuvo más justificación que una denuncia anónima" resulta un exceso. En sentido contrario, véase Corte Suprema, rol № 181-2013, de 19 de febrero de 2013. Allí, el mismo tribunal considera que "... un llamado anónimo y la constatación de que dos sujetos portaban un computador..." son suficientes indicios para proceder al control de identidad. En relación al tópico planteado, creemos que no existe razón para descartar a priori una llamada telefónica anónima como antecedente idóneo para justificar un control de identidad, cuando la información proporcionada sea precisa, verosímil y aparezca rodeada de antecedentes externos que la doten de razonabilidad. Sin embargo, en opinión de estos autores, lo crítico que subyace en este tipo de procedimientos y muchas veces invisible, es la duda que se instala respecto de la efectividad de la llamada, en el sentido que pueda ser invocada sólo como una excusa para justificar el criterio policial empleado en el caso. Ello, creemos, puede superarse estableciendo criterios más exigentes respecto de la prueba de la existencia de la llamada telefónica, mismos que permitan descartar que se trate de una referencia meramente ritual (registros sonoros, constancias escritas con indicación del número en que se efectúa, individualización clara y precisa del funcionario que la recibió, etc.).
} 
intérprete de forma previa al procedimiento, manejando la información y elementos que tenían los agentes. Sólo la presencia de indicios y la existencia de un caso fundado previo, autoriza la realización del procedimiento del artículo 85 del CPP. El control de identidad no puede validarse por haber encontrado efectivamente una ligazón entre el sujeto afectado y un delito. La existencia de un resultado de interés investigativo, no puede sanear la ausencia de los presupuestos legales que lo habilitan. Ello, en la práctica, implicaría abandonar este procedimiento al descontrol, toda vez que sería irrelevante la existencia o no de un indicio, ya que sería posible realizar todo tipo de controles, sin fundamento alguno. En aquellos casos que no hayan resultados positivos, el procedimiento normalmente no llegará a conocimiento de la autoridad, ni será revisado en su procedencia. En el caso que el control arroje resultados positivos, ello implicará su validación automática ${ }^{89}$. Si bien se trata esta advertencia última de algo que podría ser considerado una obviedad, conviene traer a la vista este asunto, puesto que no es raro ver fundamentaciones de los procedimientos haciendo alusión o directamente al hallazgo de especies provenientes de un delito, o validando la sospecha policial, aunque el motivo fuera tenue, por el encuentro posterior de un elemento ilícito.

\subsubsection{Ejecución defectuosa del control de identidad: traslado innecesario del sujeto a la unidad policial}

El asunto que nos interesa destacar, en este párrafo, ya no se sitúa en la justificación del proceder policial. Se trata acá de analizar supuestos donde el obrar de los agentes se encuentra debidamente justificado y apegado a derecho en su habilitación legal. No obstante ello, durante la ejecución del procedimiento se produce una irregularidad que contamina o vicia el procedimiento. En el caso, específicamente nos interesa acá el traslado injustificado del sujeto a la unidad policial.

El artículo 85 del CPP dispone que en el contexto del procedimiento "... la identificación se realizará en el lugar en que la persona se encontrare... el funcionario policial deberá otorgar a la persona facilidades para encontrar y exhibir estos instrumentos" (inciso $1^{\circ}$ ). Luego añade que "en caso de negativa de una persona a acreditar su identidad, o si habiendo recibido las facilidades del caso no le fuere posible hacerlo, la policía la conducirá a la unidad policial más cercana para fines de identificación. En dicha unidad se le darán facilidades para procurar una identificación satisfactoria... dejándola en libertad en caso de obtenerse dicho resultado, previo cotejo de la existencia de órdenes de

${ }^{89}$ Véase RABI (2010), p. 350; BLANCO y otros (2005), p. 55. 
detención que pudieren afectarle. Si no resultare posible acreditar su identidad, se le tomarán huellas digitales..." (inciso $3^{\circ}$ ).

Si bien, como ya señaláramos, el control de identidad comporta una de las intervenciones en materia de derechos fundamentales más tenues, de aquellas regladas como métodos al servicio de la persecución penal, la misma puede ser ejecutada por la policía con distintas intensidades, dependiendo de las circunstancias fácticas que el caso presente. El control puede implicar una vulneración leve a la libertad ambulatoria, cuando se realiza en la vía pública de manera breve y en el caso que el ciudadano logre acreditar en el lugar su identidad por un instrumento idóneo. En cambio, la afectación a la libertad será más severa, si el procedimiento de identificación no puede ser realizado en donde se encuentra el ciudadano y éste debe ser trasladado a un recinto policial, donde seguirán las actividades.

Es indudable que el control de identidad no se estableció por el legislador procesal penal para sólo recabar, por mera curiosidad o vano interés, el nombre de un sujeto concreto. Procesal y policialmente ello no tiene sentido. El correcto entendimiento del control de identidad, en nuestra opinión, implica construir necesarias referencias a los indicios, y a través de éstos, al delito que se pretende investigar o prevenir ${ }^{90}$. Por ello, no puede demonizarse, a juicio de estos autores, que la policía en el contexto del control no sólo se aboque a obtener certeza sobre quien tiene delante, sino que dentro de los medios legales que tenga disponibles, como el registro corporal, intente también verificar o descartar la posible conexión del ciudadano con algún ilícito. La mirada aséptica del instituto, considerando la propia redacción legal, sencillamente no resulta posible.

Sin embargo, debido a la propia levedad de los antecedentes que justifican la irrupción en la libertad de una persona, dentro del contexto de estos procedimientos, el legislador previó una estricta regulación de su ejercicio, estableciendo cotos que consisten en que las actividades vinculatorias o indagatorias que realice la policía, no podrán superar en intensidad y tiempo, a lo que sea necesario para identificar a un sujeto. Las necesidades que demande la identificación determinarán la intensidad del procedimiento, independiente de lo útil que podría ser para la prevención o investigación extender la privación de libertad de la persona. Si los agentes policiales, durante los momentos que dure el procedimiento identificativo (incluido el registro), no logran determinar el delito para ellos desconocido aun, o el nexo que éste tendría con el sujeto controlado, de igual forma deben ponerle término al procedimiento, una vez constatada la identidad del sujeto, pudiendo registrar todo lo que estimen

${ }^{90}$ En este sentido, véase RABI (2010), p. 334. 
relevante en relación al control, para llevar adelante a futuro pesquisas con motivo de la información que se maneja u obtenga ${ }^{91}$.

Por ello, si el sujeto controlado en la vía pública sólo es sometido a un registro corporal y únicamente retenido a efecto de indagar su vinculación con un delito, sin prestar mayor atención a la identificación del mismo, la policía habrá obrado fuera del marco legal. También habrá obrado fuera del marco legal si, conforme a sus posibilidades, no se actuó de forma expedita (inciso final del artículo 85 del CPP).También se habrán excedido del mismo los agentes que sin dar las facilidades para que el sujeto se identifique en la vía pública, sin más, lo trasladan a la unidad policial para ejecutar el procedimiento de control o para realizar derechamente otras actividades investigativas.

Siguiendo a Arias, debemos tener presente que cuando la policía decide ya conducir al sujeto controlado a la unidad policial, más allá del nombre con que designemos al estatuto jurídico que lo rige, lo que hay es una verdadera detención en su sentido amplio, entendiendo por tal cualquiera privación de libertad en un contexto judicial, que no pueda encasillarse en la prisión preventiva o en una ejecución de pena ${ }^{92}$. Lo anterior, como cualquier medida que afecte derechos fundamentales, ejecutada fuera del marco legal y de las facultades de los funcionarios públicos, acarrea la necesaria declaración de ilegalidad de la misma y, en su momento, la exclusión de toda consideración probatoria de los antecedentes recabados durante el procedimiento ${ }^{93}$.

\section{Bibliografía CitADA}

Actas Oficiales de la Comisión Constituyente. Comisión Ortúzar. Sesión No 129 celebrada en jueves 12 de junio de 1975, disponible en: http://www.leychile. cl/Consulta/antecedentes_const_1980.

\footnotetext{
${ }^{91}$ Véase, Corte Suprema, rol № 6305-2010, de 19 de octubre de 2010. El Máximo Tribunal allí se pronuncia sobre la naturaleza del procedimiento y su alcance, afirmando que "... el denominado procedimiento de 'Control de Identidad', sólo tiene por finalidad lograr o establecer con certeza la individualización de un sujeto determinado, a fin de obtener posteriormente y con arreglo a derecho y por lo que éste pueda proporcionar, antecedentes o medios probatorios ya para la indagación de presuntos, pero específicos, hechos punibles, ya sobre la individualidad de las personas que pudieron o se aprestaren a cometerlos, constituyendo una verdadera medida de seguridad o resguardo, de antecedentes, pruebas o información, que llega a su fin al establecerse la correspondiente identidad del sujeto, siendo concluyente que el legislador sólo lo permite bajo ciertos respectos y circunstancias...".

${ }_{92}$ Arias (2005) pp. 230-231. En similar sentido, véase FalCone (2012), p. 5.

${ }_{93}$ Véase en este sentido, Corte Suprema, rol № 2346-2013, de 3 de junio de 2013. La Excma. Corte sostiene que el traslado de una imputada a la unidad policial, aun a pretexto de realizarse éste a causa del entorno conflictivo del lugar donde se efectúa el control, si no se dieron en el lugar las facilidades para la identificación, hace devenir en ilícito el actuar policial.
} 
Acuña, Paulina (2013): Análisis de medidas restrictivas de Derechos Fundamentales en el D.L. No 211 y en Derecho comparado, Tesis de licenciatura, Universidad de Chile (Santiago, inédito).

Aldunate, Eduardo (2008): Derechos fundamentales (Santiago, LegalPublishing, primera edición).

AleXY, Robert (1986): Teoría de los derechos fundamentales (trad. cast. Madrid, 1993, Centro de Estudios Constitucionales, primera edición).

Álvarez, José Ramón y Rius, Francisco (2009): La entrada y registro en lugar cerrado: consideraciones procesales, jurisprudenciales y policiales (Madrid, Tecnos, primera edición).

Basso, Osvaldo (2013): Procedencia de la exclusión de la prueba ilícita de descargo (Santiago, Librotecnia, primera edición).

Bernal, Carlos (1989): "Estructura y límites de la ponderación" disponible en: $<$ http://publicaciones.ua.es/filespubli/pdf/02148676RD49949854.pdf>.

Bernal, Carlos (2005): El principio de proporcionalidad y los derechos fundamentales (Madrid, Centro de Estudios Políticos y Constitucionales, primera edición).

BofILL, Jorge (1988): "Las prohibiciones de prueba en el proceso penal", disponible en: <http://www.rdpucv.cl/index.php/rderecho/article/view/217/201>.

Cabezudo Bajo, María José (2004): La inviolabilidad del domicilio y el proceso penal, lustel, Madrid.

CAFFerATA, José (1998): La prueba en el proceso penal (Buenos Aires, Ediciones De Palma, tercera edición).

CAROCCA, Alex (1998): “Una primera aproximación al tema de la prueba ilícita en Chile", disponible en: <http://www.redalyc.org/articulo.oa?id=19740213>.

DAMASKA, Mirjam R. (1997): Evidence Law Adrift (New Haven, Yale University Press).

DuCE, Mauricio y RieGo, Cristián (2007): Proceso penal (Santiago, Editorial Jurídica de Chile, primera edición).

ECheverría, Isabel (2010): Los derechos fundamentales y la prueba ilícita (Santiago, Ediciones Jurídicas de Santiago, primera edición).

ECKHOFF, Rolf (1992): Der Grundrechtseingriff (Kölhn, Heymanns, primera edición).

Falcone, Diego y Oliver, Guillermo (2012): Apuntes de Derecho Procesal Penal (Valparaíso, inédito).

FERRAJOLI, Luigi (1989): Derecho y razón, teoría del garantismo penal (Madrid, trad. cast., 1995). 
Garay, Guillermo e InChausti, Santiago (2006): "El allanamiento de domicilio: la orden judicial y su fundamentación", en HaZAN, Luciano y PLAZAS, Florencia (coords.), Garantías constitucionales en la investigación penal: un estudio crítico de la jurisprudencia (Buenos Aires, Editores del Puerto, primera edición).

Gascón, Marina (s.f.): "La prueba judicial: valoración racional y motivación", disponible en: http://www.uclm.es/postgrado.derecho/_02/web/materiales/ filosofia/Prueba.pdf.

GonzÁlez, Lionel (2010): "La regla de exclusión por ilicitud probatoria en Chile", Revista Brasileira de Ciencias Criminais, año 18, № 85, julio-agosto 2010 : pp. 353-292.

González-Cuéllar, Nicolás (1990): Proporcionalidad y derechos fundamentales en el proceso penal (Madrid, Colex, primera edición).

Guariglia, Fabricio (2005): Concepto, fin y alcance de las prohibiciones de valoración probatoria en el procedimiento penal (Buenos Aires, Editores del Puerto, primera edición).

HeRNÁNDEZ, Héctor (2005): "La exclusión de la prueba ilícita en el nuevo proceso penal chileno", Colección de Investigaciones Jurídicas, № 2.

HinOJOSA SEGovia, Rafael (1996): Diligencia de entrada y registro en lugar cerrado en el proceso penal, Editorial de Derecho Reunidas, Madrid.

Horvitz, María Inés y López, Julián (2002): Derecho procesal penal chileno (Santiago, Editorial Jurídica de Chile, primera edición), tomos I y II.

KRAUSE, María Soledad (2005): "Algunas consideraciones sobre la exclusión de la prueba ilícita en el procedimiento penal", Revista Procesal Penal, № 30, febrero 2005, pp. 13-21.

López-Fragoso, Tomás (1991): Las interceptaciones telefónicas en el proceso penal (Madrid, Colex, primera edición).

MAIER, Julio (2011): Derecho procesal penal, III: Parte general, Actos procesales (Buenos Aires, Editores del Puerto, primera edición).

Martínez, Vicente (2002): "La práctica de la entrada y registro domiciliario", Revista Jurídica Magestri et Doctores 8 (Argentina, 2002), 2.

Maturana, Cristián y Montero, Raúl (2010): Derecho procesal penal (Santiago, LegalPublishing, primera edición), tomos I y II.

MıNı, Mario (2005): La prueba ilícita en el proceso penal (Santiago, Metropolitana Ediciones, primera edición).

MiRANDA, Manuel (1999): El concepto de prueba ilícita y su tratamiento en el proceso penal (Barcelona, J.M. Bosch Editor, primera edición). 
MoreiRa, Alejandro (2009): "Delitos tributarios y recopilación de antecedentes. Comentarios a propósito de un fallo dictado por el Tribunal Constitucional", Revista Jurídica del Ministerio Público 41, pp. 185-212.

NúÑEz, Cristóbal (2001): Tratado del proceso penal y del juicio oral (Santiago, Editorial Jurídica de Chile, primera edición), tomo I.

Núñez, Raúl y Pérez, Álvaro (2013): Manual de Derecho Procesal Civil. Parte general (Santiago, Thomson Reuters, primera edición).

Palomo, Yolanda (2004): "Diligencia de entrada y registro en domicilio", Revista Peruana de Derecho Procesal 7, pp. 303 y ss.

PIEROTH, Bodo y Schlink, Bernhard (1989): Grundrecht. Staatasrecht II (Heidelberg, CF. Müller, primera edición).

RIVES, Antonio (2004): La diligencia de entrada y registro domiciliario (Barcelona, Bosch S.A., 2004).

Roxin, Claus (1997): "Zur richterlichen Kontrolle von Durchsuchungen und Beschlagnahmen", Strafverteidiger, 1997, pp. 654-656.

Salas Astrain, Jaime (2009): Problemas del proceso penal. Investigación, etapa intermedia y procedimientos especiales (Librotecnia, Santiago, 2009).

Schmalz, Dieter (1997): Grundrecht (Baden-Baden, Nomos, tercera edición).

ZaPATA, María Francisca (2004): La prueba ilícita (Santiago, LexisNexis, primera edición).

Zavidich Diomedi, Carolina: El registro de vehículos, en Revista Jurídica del Ministerio Público 38 (marzo 2009), pp. 147-156. 